\title{
Pyramidal neurons in the superficial layers of rat retrosplenial cortex exhibit a late-spiking firing property
}

\author{
Tohru Kurotani $\cdot$ Toshio Miyashita $\cdot$ Marie Wintzer • \\ Tomokazu Konishi $\cdot$ Kazuhisa Sakai $\cdot$ Noritaka Ichinohe • \\ Kathleen S. Rockland
}

Received: 4 October 2011/ Accepted: 10 February 2012/Published online: 1 March 2012

(C) The Author(s) 2012. This article is published with open access at Springerlink.com

\begin{abstract}
The rodent granular retrosplenial cortex (GRS) is reciprocally connected with the hippocampus. It is part of several networks implicated in spatial learning and memory, and is known to contain head-direction cells. There are, however, few specifics concerning the mechanisms and microcircuitry underlying its involvement in spatial and mnemonic functions. In this report, we set out to characterize intrinsic properties of a distinctive population of small pyramidal neurons in layer 2 of rat GRS. These neurons, as well as those in adjoining layer 3, were found to exhibit a late-spiking (LS) firing property. We established by multiple criteria that the LS property is a consequence of delayed rectifier and A-type potassium channels. These were identified as Kv1.1, Kv1.4 and Kv4.3 by Genechip analysis, in situ hybridization, single-cell
\end{abstract}

T. Kurotani $\cdot$ T. Miyashita $\cdot$ M. Wintzer $\cdot$ N. Ichinohe $\cdot$

K. S. Rockland

Lab for Cortical Organization and Systematics, RIKEN Brain

Science Institute, 2-1 Hirosawa, Wako 351-0198, Japan

T. Kurotani $(\square)$

ERATO, Okanoya Emotional Information Project, Japan Science and Technology Agency, 2-1 Hirosawa, Wako 351-0198, Japan e-mail: kurotani@brain.riken.jp

T. Konishi

Faculty of Bioresource Sciences, Akita Prefectural University,

Akita 010-0195, Japan

K. Sakai · N. Ichinohe

Department of Ultrastructural Research, National Institute of Neuroscience, Kodaira 187-8551, Japan

K. S. Rockland

Picower Institute for Learning and Memory, Massachusetts Institute of Technology, Cambridge, MA 02139, USA reverse transcriptase-polymerase chain reaction, and pharmacological blockade. The LS property might facilitate comparison or integration of synaptic inputs during an interval delay, consistent with the proposed role of the GRS in memory-related processes.

Keywords Retrosplenial cortex · Pyramidal neuron · Firing property $\cdot$ Potassium channel $\cdot$ Late spiking

\section{Introduction}

The granular retrosplenial (GRS) cortex of rodents is an important structure in several networks involved in spatial learning and memory (Cooper and Mizumori 2001; Pothuizen et al. 2008; Garden et al. 2009; Vann et al. 2009; Aggleton et al. 2010). Consistent with this, lesion-behavior experiments have demonstrated that damage to the GRS results in specific impairments in spatial working memory (Keene and Bucci 2009), and selective activations in the GRS have been reported in spatial tasks using immediate early genes (Pothuizen et al. 2009). This aspect of GRS function has been attributed to its dense reciprocal connections with the hippocampal formation, with the idea that the two areas operate conjointly to support spatial memory (Mizumori et al. 2000). One recent report, corroborating earlier studies, found that hippocampal lesions produce marked reductions in the levels of immediate early gene proteins in the GRS, subsequent to behavioral tasks (Albasser et al. 2007). Several other recent investigations provide evidence that disrupting the dense reciprocal connections between the GRS and anterior thalamic nucleus results in a striking loss of synaptic plasticity in the superficial layers of the GRS (Garden et al. 2009; Wright et al. 2010). 
The underlying substrates of GRS function are complex, and are likely to incorporate both intrinsic cellular specializations as well as network properties. Theta-rhythmic activity has been postulated to coordinate activity in distributed systems, including the GRS, during mnemonic processes (Kirk and MacKay 2003). Detailed information for the GRS, however, is largely limited to anatomical characterization of individual neuronal types (Vogt and Peters 1981; Wyss et al. 1990), and identification of the major inputs and outputs (Sripanidkulchai and Wyss 1986; van Groen and Wyss 1990; Wyss and van Groen 1992; Shibata et al. 2004; Aggleton et al. 2010).

A distinctive feature of the rodent GRS is an accentuated layer 2, consisting mainly of closely packed, callosally projecting small pyramidal neurons (Wyss et al. 1990; Ichinohe et al. 2008). In the rat, the apical dendrites of these neurons form prominent bundles, which co-localize with parvalbumin-positive dendrites (Ichinohe and Rockland 2002) and with patches of thalamic terminations (Shibata 1993).

As a step toward elucidating synaptic properties of this neuronal population, we recorded from slice preparations of the rat GRS to characterize intrinsic membrane characteristics. We found that the majority of pyramidal neurons in layer 2 , and some in underlying layer 3 , have a distinctive late-spiking (LS) firing pattern, where an initial rapid rise in membrane potential is followed by a slowly ramping depolarization that leads to an action potential firing near the end of a just-threshold current step. This LS property is unusual for pyramidal neurons, but has been previously reported for pyramidal neurons of rat perirhinal cortex (Beggs et al. 2000; McGann et al. 2001; Moyer et al. 2002).

We further established that the LS property is a consequence of delayed rectifier and A-type potassium channels. These were identified as Kv1.1, Kv1.4 and Kv4.3 by several corroborating techniques; namely, Genechip analysis, in situ hybridization, single-cell reverse transcriptasepolymerase chain reaction (RT-PCR), and pharmacological blockade.

\section{Materials and methods}

Slice preparation and recording of intrinsic membrane properties

Postnatal day 20-35 Wistar rats were deeply anesthetized with isoflurane and decapitated. The brain was quickly removed and immersed into chilled and oxygenated $(95 \%$ $\mathrm{O}_{2}$ and $5 \% \quad \mathrm{CO}_{2}$ ) artificial cerebrospinal fluid (ACSF) containing (in $\mathrm{mM}$ ): $\mathrm{NaCl} 126, \mathrm{KCl} 3, \mathrm{NaH}_{2} \mathrm{PO}_{4} 1.2$, $\mathrm{MgSO}_{4}$ 1.3, $\mathrm{CaCl}_{2}$ 2.4, $\mathrm{NaHCO}_{3}$ 26, and glucose 10.
Coronal or horizontal slices (300 $\mu \mathrm{m}$ thick) were prepared from GRS cortex using a Pro-7 vibrating microtome (Dosaka, Kyoto, Japan). After cutting, the slices were transferred to an interface-type chamber and perfused with oxygenated ACSF at $32-34^{\circ} \mathrm{C}$ for at least $1 \mathrm{~h}$ for recovery. Then one slice was selected and placed in a recording chamber continuously perfused with oxygenated ACSF ( $2 \mathrm{ml} / \mathrm{min}$ ) at $27-30^{\circ} \mathrm{C}$. Layer 2 of GRS cortex was easily visualized by virtue of its cell density, and neurons were targeted for recording on the basis of a pyramidal-like shape as visualized by infra-red differential interference contrast video microscopy (BX-50, Olympus, Tokyo, Japan). Whole-cell recordings were conducted with borosilicate patch pipettes (BF150-110-10, Sutter Instrument, Novato, CA, USA) filled with an internal solution containing (in $\mathrm{mM}$ ): K-gluconate $150, \mathrm{NaCl} 10, \mathrm{MgSO}_{4} 5$, HEPES 10 and EGTA 0.3 , with $3 \mathrm{mg} / \mathrm{ml}$ biocytin and $\mathrm{pH}$ 7.3 adjusted with $\mathrm{KOH}$. Current-clamp recordings were made by an Axoclamp 2B amplifier (Molecular Devices Corp., Sunnyvale, CA, USA) and intrinsic firing properties were investigated by injecting step-depolarizing currents (duration $1 \mathrm{~s}$, amplitude $\pm 10-200 \mathrm{pA}$ ). In some of the experiments, spontaneous postsynaptic responses were suppressed by perfusing $40 \mu \mathrm{M}$ DNQX, $25 \mu \mathrm{M}$ DL-APV and $20 \mu \mathrm{M}$ bicuculline methiodide. To confirm that the firing pattern of the neurons was unchanged at $36^{\circ} \mathrm{C}$, intracellular recordings from GRS layer 2 neurons were performed using sharp glass microelectrodes (containing $2 \mathrm{M} \mathrm{K}$-gluconate and $10 \mathrm{mM} \mathrm{KCl}$, resistance $>150 \mathrm{M} \Omega$ ) in a Haas type interface chamber. In all electrophysiological recordings, the electrode resistance was effectively canceled out using a bridge balance circuit equipped in Axoclamp 2B.

After the recording, the cells were filled with biocytin by diffusive loading through the patch pipette for 10-15 min. The patch pipette was slowly retracted from the cell after the filling so that the cell membrane was successfully resealed. One to eight neurons were filled per slice, and the slice was then transferred back to the interface-type chamber for more than $1 \mathrm{~h}$ for completion of biocytin transport. Slices were fixed overnight at $4{ }^{\circ} \mathrm{C}$ in $4 \%$ paraformaldehyde (PFA) containing $0.3 \%$ picric acid, washed four times for $10 \mathrm{~min}$ each in phosphate buffered saline (PBS) at room temperature, and treated with $1 \% \mathrm{H}_{2} \mathrm{O}_{2}$ in $0.1 \mathrm{M}$ PBS for $20 \mathrm{~min}$. After four rinses of $5 \mathrm{~min}$ each in $0.1 \mathrm{M}$ PBS, the slices were incubated overnight in an avidin-biotin complex (one drop of each reagent for $7 \mathrm{ml}$ of $0.1 \mathrm{M}$ PBS containing 1\% TritonX; ABC Elite kits, Vector Laboratories, Burlingame, CA, USA) at room temperature. Next day, sections were rinsed four times in $0.1 \mathrm{M}$ phosphate buffer (PB) for $10 \mathrm{~min}$ each, and DAB histochemistry $(25 \mathrm{mg} / 50 \mathrm{ml}$, in $0.1 \mathrm{M} \mathrm{PB})$ was performed with the addition of $0.03 \%$ nickel ammonium sulfate. 
In some experiments, the same slice preparation, recording and staining procedures were carried out for the pyramidal neurons in layers 3 and 5 of GRS, layer 2 of the barrel field cortex $(\mathrm{BF})$ of adult rats for comparison.

To compare the dendritic branching pattern, the stained pyramidal neurons in layer 2 of GRS and of BF were investigated by Sholl analysis. Labeled pyramidal neurons were analyzed using Neurolucida (Micro-BrightField Inc, Colchester, VT). A series of concentric circles, with radius increasing by $10 \mu \mathrm{m}$ increments, were drawn starting from the center of the cell soma. Then the number of intersections made by the particular dendrite with each circle was counted using NeuroExplorer (Micro-BrightField Inc), and plotted against the distance from the soma. For statistical analyses of data obtained from the electrophysiological and morphological experiments, Student's $t$ test was employed unless otherwise mentioned.

\section{Microarray data}

From a parallel investigation involving rat GRS (Miyashita et al. 2010), we had microarray data for genes which are highly and specifically expressed in GRS layer 2. Briefly, concerning the criteria for gene selection, we compared gene expression profiles for layer 2 of GRS, layer 5 of GRS, and layer 2 of the somatosensory barrel cortex at postnatal day 28. Significance in expressional change between layers 2 of GRS and BF was tested gene-wise using paired $t$ test on perfect match (PM) cell data of microarray (GeneChip, Rat Expression 2302.0 Array; Affymetrix, Santa Clara, CA). Among the corresponding PM data of a gene, all the data that were out of the plausible signal range (Konishi 2004, 2008), and those within the detected area but caused by dust contamination (Konishi 2006), were removed. Then, $t$ test was performed by cell-wise comparison, using a threshold of 0.01 . Genes were further selected that showed three times higher expression levels in layer 2 than in layer 5 of GRS (Table 1). Full details are given in Miyashita et al. 2010.

In situ hybridization for Kv1.4

PCR primers for Kv1.4 (5'-CATAATTGTGGCGAACG TG- $3^{\prime}$ and $5^{\prime}$-TTTTGAAAGATTCGGCTGCT- $3^{\prime}$ ) were designed based on the rat cDNA sequence of Kv1.4 (GenBank No. NM_012971). The DNA fragments were produced by RT-PCR from rat brain cDNA. PCR fragments were ligated into the pGEMt-easy (Promega, Madison, WI) vector. The plasmids were extracted and linearized by Asp718 or Xhol before being used for the template of antisense or sense probes. The digoxigenin (DIG)-dUTP labeling kit (Roche, Basel, Switzerland) was used for in vitro transcription.

Two adult rats were used for in situ hybridization for Kv1.4 mRNA. Animals were anesthetized with Nembutal intraperitoneally $(100 \mathrm{mg} / \mathrm{kg})$, and perfused transcardially, in sequence, with $0.9 \% \mathrm{NaCl}$ and $0.5 \% \mathrm{NaNO}_{2}$ for $1 \mathrm{~min}$, and $4 \%$ PFA in $0.1 \mathrm{M}$ PB for $10 \mathrm{~min}$. Brains were removed

Table 1 List of Kv channel genes that were highly expressed in GRS layer 2

\begin{tabular}{lllll}
\hline HGNC name & IUPHAR name & Ratio (GRSL2/BFL2) & $P$ value & Ratio (GRSL2/GRSL5) \\
\hline Kend3 & Kv4.3 & 3.55 & $5.05 \mathrm{E}-17$ & $\mathbf{8 . 6 5}$ \\
Kena4 & Kv1.4 & 4.33 & $1.67 \mathrm{E}-15$ & $\mathbf{4 . 2 4}$ \\
Kens1 & Kv9.1 & 2.27 & $1.58 \mathrm{E}-07$ & 2.53 \\
Kend2 & Kv4.2 & $5.46 \mathrm{E}-08$ & 2.25 \\
Kena1 & Kv1.1 & $\mathbf{5 . 0 5}$ & $5.37 \mathrm{E}-22$ & 1.57 \\
Kend2 & Kv4.2 & 1.22 & $4.35 \mathrm{E}-05$ & 1.26 \\
Kenc1 & 1.80 & $3.12 \mathrm{E}-10$ & 1.22 \\
Keng2 & 1.25 & $1.49 \mathrm{E}-03$ & 1.02 \\
Kenb1 & Kv3.1 & $6.98 \mathrm{E}-06$ & 0.93 \\
Kcns3 & Kv2.1 & 1.24 & $1.62 \mathrm{E}-12$ & 0.92 \\
Kenc3 & Kv9.3 & 2.39 & $1.01 \mathrm{E}-03$ & 0.88 \\
Kenab1 & Kv3.3 & 1.40 & $9.62 \mathrm{E}-19$ & 0.77
\end{tabular}

The expression level of each gene in GRS layers 2, 5 and BF layer 2 was calculated as $z$ score. Then significant difference in expression levels of each gene in GRS layer 2 and BF layer 2 was calculated by Welch's paired two-sided $t$ test, and the $P$ values were determined (Konishi 2004 , 2006, 2008). Kv channel genes, having expression ratio $>1$ and $P<0.01$ in GRS layer 2 compared to BF layer 2, were selected. The genes are sorted by the expression ratio of those in GRS layer 2 to in GRS layer 5. Note that Kv4.3 and Kv1.4 genes are much more highly expressed in GRS layer 2 than in GRS layer 5 (ratio; 8.65 and 4.24, respectively). It should be also noted that Kv1.1 was highly expressed in GRS layer 2, compared to BF layer 2 (ratio; 5.05)

HGNC HUGO Gene Nomenclature Committee, IUPHAR International Union of Pharmacology 
and postfixed in the same fixative for $2 \mathrm{~h}$, and then immersed into $30 \%$ sucrose in $0.1 \mathrm{M}$ PB until sinking (20-40 h). Sections were cut (in the coronal plane, at $30 \mu \mathrm{m}$ thickness) using a sliding microtome. Sections were washed in $0.1 \mathrm{M} \mathrm{PB}$, and again postfixed with $4 \%$ PFA in $0.1 \mathrm{M}$ PB for $10 \mathrm{~min}$. After washing in $0.1 \mathrm{M} \mathrm{PB}$, sections were treated with $1 \mu \mathrm{g} / \mathrm{mL}$ proteinase $\mathrm{K}$ for $10 \mathrm{~min}$ at $37^{\circ} \mathrm{C}$, acetylated, then incubated in hybridization buffer containing $0.5-1.0 \mu \mathrm{g} / \mathrm{mL}$ DIG-labeled riboprobes at $60^{\circ} \mathrm{C}$ over night. The sections were sequentially treated for $15 \mathrm{~min}$ at $55^{\circ} \mathrm{C}$ in $2 \times$ standard sodium citrate (SSC)/50\% formamide $/ 0.1 \% \mathrm{~N}$-lauroylsarcosine, twice; for $30 \mathrm{~min}$ at $37^{\circ} \mathrm{C}$ in RNase buffer $(10 \mathrm{mM}$ Tris- $\mathrm{HCl}, \mathrm{pH} 8.0,1 \mathrm{mM}$ EDTA, $500 \mathrm{mM} \mathrm{NaCl}$ ) containing $20 \mu \mathrm{g} / \mathrm{mL}$ RNase A (Sigma, St. Louis, MO, USA); for $15 \mathrm{~min}$ at $37^{\circ} \mathrm{C}$ in $2 \times$ $\mathrm{SSC} / 0.1 \% \mathrm{~N}$-lauroylsarcosine, twice; for $15 \mathrm{~min}$ at $37^{\circ} \mathrm{C}$ in $0.2 \times \mathrm{SSC} / 0.1 \% \mathrm{~N}$-lauroylsarcosine, twice. The hybridized probe was detected by alkaline phosphatase-conjugated anti-DIG antibody with DIG detection kits (Roche Diagnostics, Basel, Switzerland). Controls with sense riboprobes showed no hybridization signal.

\section{Single-cell RT-PCR experiment}

To assess potassium channel mRNAs across individual LS pyramidal neurons, single-cell RT-PCR experiments were performed. Recording pipettes were prepared as above, except that an RNase inhibitor (Takara, Otsu, Japan, final concentration, $0.5 \mathrm{U} / \mu \mathrm{l}$ ) was added to the pipette solution. Pipettes were filled with $5 \mu$ of the solution. Directly after patch-clamp recording, the contents of the cell including the nucleus were aspirated into the patch electrode. The small size of LS neurons made it difficult to obtain enough cytoplasm for single-cell RT-PCR without including the nucleus. However, by employing the intron-spanning assay, it was possible to effectively differentiate between genome-derived and mRNA-derived signals (Liss and Roeper, 2004). The electrode tip was broken off into a reaction tube containing $5 \mu \mathrm{l}$ diethylpyrocarbonate treated water containing RNase inhibitor $(0.5 \mathrm{U} / \mu \mathrm{l}$, RNase OUT, Takara), and the tubes were briefly stored on ice until use.

\section{Reverse transcription $(R T)$}

mRNA was reverse transcribed with the Superscript III CellsDirect cDNA Synthesis System kit (Invitrogen, San Diego, CA, USA). The reverse transcription mixture containing the cell contents, $1 \mu \mathrm{l}$ Oligo(dT) $20(50 \mathrm{mM})$ and $0.5 \mu \mathrm{l} \mathrm{dNTP}$ mix $(10 \mathrm{mM})$ was first heated to $70^{\circ} \mathrm{C}$ for $5 \mathrm{~min}$ and incubated on ice for $2 \mathrm{~min}$. Single-strand cDNA synthesis was carried out at $50^{\circ} \mathrm{C}$ for $50 \mathrm{~min}$, after the addition of $3 \mu \mathrm{l} 5 \times \mathrm{RT}$ buffer, $0.5 \mu \mathrm{l}$ RNase OUT (40 U/ $\mu \mathrm{l}$ ), $0.5 \mu \mathrm{l}$ DTT $(0.1 \mathrm{M})$ and $0.5 \mu \mathrm{l}$ Superscript III RT
(200 U/ $\mu \mathrm{l})$ in a final volume of $15 \mu \mathrm{l}$. This reaction was terminated at $85^{\circ} \mathrm{C}$ for $5 \mathrm{~min}$. Before PCR amplification, $1 \mu \mathrm{l}$ of RNase $(2 \mathrm{U} / \mu \mathrm{l})$ was added and the samples incubated at $37^{\circ} \mathrm{C}$ for $20 \mathrm{~min}$. Ten microliters of RT products were used for following PCR amplification.

\section{PCR amplification}

Multiplex PCR conditions were optimized using total RNA purified from rat brain. Primer pairs were designed to locate on different exons separated by introns to prevent amplification of genomic DNA. Under these conditions, subsequent gel analysis did not detect nonspecific products. Controls for contaminating artifacts using sterile water instead of DNA, and PCR done on samples without reverse transcriptase did not detect any product. A multiplex tworound single-cell PCR was carried out for simultaneous detection of vesicular glutamate transporter 1 (VGluT1), $\mathrm{GABA}_{\mathrm{A}}$ receptor $\alpha 1$ subunit, and voltage-activated potassium channels $\mathrm{Kv} 1.1, \mathrm{Kv} 1.2, \mathrm{Kv} 1.4, \mathrm{Kv} 3.1$ and Kv4.3. $\mathrm{GABA}_{\mathrm{A}}$ receptor $\alpha 1$ subunit and $\beta$-actin were used as a positive control.

The first amplification round consisted of $15 \mathrm{~min}$ hot start at $95^{\circ} \mathrm{C}$, followed by 40 cycles $\left(94^{\circ} \mathrm{C}\right.$ for $30 \mathrm{~s}, 57^{\circ} \mathrm{C}$ for $1.5 \mathrm{~min}$ and $72^{\circ} \mathrm{C}$ for $1 \mathrm{~min}$ ). All genes were simultaneously amplified in a single tube containing $10 \mu \mathrm{l}$ of the RT product, $250 \mathrm{nM}$ of each of the outer primers, $40 \mu \mathrm{M}$ of each dNTPs, $2.5 \mathrm{U}$ Ex Taq Hot Start DNA Polymerase (Takara) and $1 \times$ PCR buffer (Takara) in a final volume of $50 \mu \mathrm{l}$.

A second round of PCR consisted of $15 \mathrm{~min}$ hot start at $95^{\circ} \mathrm{C}$, followed by 40 cycles $\left(94^{\circ} \mathrm{C}\right.$ for $30 \mathrm{~s}, 55^{\circ} \mathrm{C}$ for $1 \mathrm{~min}$ and $72^{\circ} \mathrm{C}$ for $1 \mathrm{~min}$ ), and terminated at $72^{\circ} \mathrm{C}$ for $7 \mathrm{~min}$. In this round, each gene was individually amplified in a separate test tube containing: $1 \mu \mathrm{l}$ of the first PCR product (template), $250 \mathrm{nM}$ of each nested (inner) primers, $30 \mu \mathrm{M}$ of each dNTP, 2 U Ex Taq Hot Start DNA Polymerase (Takara) and $1 \times$ PCR buffer (Takara) in a final volume of $30 \mu \mathrm{l}$. The products of the second PCR were analyzed by $2 \%$ agarose gel electrophoresis (see Fig. 9 for example). Primers used for the experiment are shown in Table 2.

\section{Pharmacology}

As blockers of $\mathrm{Kv}$ channels, we used dendrotoxin-K (DTXK) $(100 \mathrm{nM}$ for $\mathrm{Kv} 1.1)$, CP-339818 (1-3 $\mu \mathrm{M}$ for Kv1.4) and nicotine $(100 \mathrm{nM}$ for Kv4.3). Drugs were bath administrated after recording intrinsic membrane and firing properties of layer 2 pyramids in normal ACSF, and changes in the firing pattern were monitored at $0.5-1 \mathrm{~min}$ intervals over $10-15 \mathrm{~min}$ by applying $70-110 \mathrm{pA}$ depolarizing current pulses. 
Table 2 List of primers used for the single-cell RT-PCR experiment

\begin{tabular}{|c|c|}
\hline \multirow[t]{2}{*}{ Kv1.1 outer } & Forward: 5'-TGCCCATGAAGTAGTCTGTG-3' \\
\hline & Reverse: 5'-ATCCACTTCTGAAGGTCAGG-3' \\
\hline \multirow[t]{2}{*}{ Kv1.1 inner } & Forward: 5'-CGTGGAACACCATGTAACAG-3' \\
\hline & 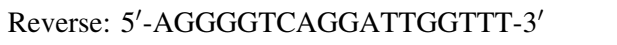 \\
\hline \multirow[t]{2}{*}{ Kv1.2 outer } & Forward: 5'-GGGGACAGAGTTAGCTGAGA-3' \\
\hline & СCTGTATCTCCATGT-3' \\
\hline \multirow[t]{2}{*}{ Kv1.2 inner } & Forward: 5'-GTCCAGACACTCCAAAGGTC-3' \\
\hline & Reverse: 5'-TCTCCCGGTGGTAGAAGTAG-3' \\
\hline \multirow[t]{2}{*}{ Kv3.1 outer } & Forward: 5'-CCTGCTGTGACTGTATGCTC-3' \\
\hline & Reverse: 5'-CCTGAACTGGAGGGACTCT-3' \\
\hline \multirow[t]{2}{*}{ Kv3.1 inner } & GTCAGGGACTAAGGAT- $3^{\prime}$ \\
\hline & Reverse: 5'-CACTGGAGCTACACACCAAG-3' \\
\hline \multirow[t]{2}{*}{ Kv1.4 outer } & GTCAGTTGCCCATACCTACC-3' \\
\hline & Reverse: 5'-CTCGGGACCACCTTTACTAT-3' \\
\hline \multirow[t]{2}{*}{ Kv1.4 inner } & Forward: 5'-AAGAAGGGGTCAAGGAGTCT-3' \\
\hline & Reverse: 5'-TAATGCCTCCCTCTTCTCC-3' \\
\hline \multirow[t]{2}{*}{ Kv4.3 outer } & Forward: 5'-AAGATGCCTTGAGGTCTGAG-3' \\
\hline & Reverse: $5^{\prime}$-AGGATGAAGACAGGGAGACA-3' \\
\hline \multirow[t]{2}{*}{ Kv4.3 inner } & Forward: 5'-AGTGAGCCTCAGGGTTAGTG-3' \\
\hline & Reverse: 5'-CAAAACACCAGGACTCCTCT-3' \\
\hline \multirow[t]{2}{*}{$\beta$-actin outer } & Forward: 5'-ACACGGCATTGTAACCAACT-3' \\
\hline & Reverse: 5'-CATTGCCGATAGTGATGACC-3' \\
\hline \multirow[t]{2}{*}{$\beta$-actin inner } & Forward: 5'-AGAAGATTTGGCACCACACT-3' \\
\hline & Reverse: 5'-CCATCTCTTGCTCGAAGTCT-3' \\
\hline \multirow[t]{2}{*}{$\begin{array}{l}\mathrm{GABA}_{\mathrm{A}} \\
\text { outer }\end{array}$} & $\begin{array}{l}\text { Forward: } 5^{\prime}- \\
\text { ACGACCGTTCTGACCATGACAACCT-3' }\end{array}$ \\
\hline & $\begin{array}{l}\text { Reverse: } 5^{\prime}- \\
\text { AAAGATTCCAAATAGCAGCGGAAAG-3' }\end{array}$ \\
\hline \multirow[t]{2}{*}{$\begin{array}{l}\mathrm{GABA}_{\mathrm{A}} \\
\text { inner }\end{array}$} & $\begin{array}{l}\text { Forward: } 5^{\prime}- \\
\text { CTCCTACAGCAACCAGCTATACCC-3' }\end{array}$ \\
\hline & Reverse: 5'-GCGGTTTTGTCTCAGGCTTGA \\
\hline \multirow[t]{2}{*}{ VGluT1 outer } & Forward: 5'-GGCCCCTCCCTTAGAACG-3' \\
\hline & Reverse: $5^{\prime}$-CCTCCGATGGGTACGATGAT \\
\hline \multirow[t]{2}{*}{ VGluT1 inner } & Forward: 5'-CCTTTTGCGGTTCCTATGC-3' \\
\hline & Reverse: $5^{\prime}$-AATGTATTTGCGCTCCTCCTC-3' \\
\hline
\end{tabular}

\section{Results}

Layer 2 in the rat GRS is densely populated by small pyramidal neurons and was readily identified by differential interference contrast microscope. Whole-cell recordings were made under current-clamp condition in pyramidal neurons to record passive membrane and intrinsic firing properties in response to depolarizing and hyperpolarizing step current injections (duration $=1 \mathrm{~s}$, except for test recordings of 5-8 s). To evaluate laminar specificity of firing properties, we compared recordings from pyramidal neurons in the rat GRS layer 3, GRS layer 5 , layer 2 of BF cortex, and, with smaller sample sizes, from the rat presubiculum and perirhinal cortex. Neurons with resting membrane potential more negative than $-55 \mathrm{mV}$ and overshooting action potentials were selected for further analyses. Properties of passive membrane and action potential for the recorded neurons are indicated in Table 3.

Biocytin filling confirmed that the LS neurons were pyramidal. That is, dendrites were studded with spines and an apical dendrite was visible, extending into upper layer 1 (Figs. 1,2). The apical dendrite was typically unbranched in its proximal portion, or had only $2-3$ main bifurcations in layer $1 \mathrm{c}$.

A more extensive tuft formed distally in layers $1 \mathrm{a}$ and 1b. Basal dendrites within layer 2 and/or 3 were prominently studded with spines. Slight morphological variations were evident, as described by previous Golgi studies (Vogt and Peters 1981; Fig. 5 in Wyss et al. 1990). Axon collaterals occurred in layers $1-6$, being more abundant in layer 5 and 6 in our material. Long axonal segments could be followed up to about $350 \mu \mathrm{m}$ from the soma, especially in layers 1 and 2 . These had evidently been cut by the slicing procedure, and probably extended further. The average cell body size of layer 2 pyramids was significantly smaller than that of layer 5 pyramids in GRS $(P<0.01$ for both of the minor and major axes, Table 3 ).

Subdivisions of layer 1 are determined following the criteria of Vogt et al. 1981. Layer 1a is subjacent to the pia and layer $1 \mathrm{c}$ is above layer 2 . Layer $1 \mathrm{~b}$ is identified by approximation as the middle sublayer.

Firing and intrinsic membrane properties

\section{GRS layer 2 pyramidal neurons}

Of 138 layer 2 pyramids recorded in GRS, 130 neurons (94\%) showed a distinctive LS firing pattern. This was characterized by an initial rapid rise in membrane potential followed by a slowly ramping depolarization. Layer 2 LS neurons demonstrate a significantly hyperpolarized resting membrane potential $(-75 \pm 0.62 \mathrm{mV}, n=130$, Fig. 3a; Table 3) compared with that of GRS layer 5 neurons $(P<0.01$, Table 3). Voltage responses of LS neurons to hyperpolarizing current steps demonstrated little or no sag at the initial hyperpolarization phase, suggesting a weak expression of hyperpolarization-activated cation channels in these neurons (Fig. 3a). The first action potential occurred near the end of a just-suprathreshold current step (Fig. 3b). LS neurons have a very high input resistance (420 $\pm 15 \mathrm{M} \Omega$, Fig. 3c; Table 3). This implies that LS neurons have a small cell body, as reported by others (Wyss et al. 1990) and confirmed in our morphological observation (Figs. 1, 2; Table 3). Because of a high input resistance, the threshold level was not always sharply determined. For 15 neurons in which we could sharply 
Table 3 Properties of LS pyramidal neurons in GRS layers 2 and 3, and RS pyramidal neurons in GRS layer 5 and BF layer 2

\begin{tabular}{lllcccc}
\hline & Soma size (minor and major axes, $\mu \mathrm{m})$ & $V_{\text {rest }}(\mathrm{mV})$ & $R_{\text {in }}(\mathrm{M} \Omega)$ & $\begin{array}{l}\text { AP threshold } \\
(\mathrm{mV})\end{array}$ & $\begin{array}{l}\text { AP height } \\
(\mathrm{mV})\end{array}$ & $\begin{array}{l}\text { AP half width } \\
(\mathrm{ms})\end{array}$ \\
\hline GRS L2 $(n=130)$ & $(11 \pm 0.31) \times(18 \pm 0.47)$ & $-75 \pm 0.62$ & $420 \pm 15$ & $-35 \pm 0.85$ & $93 \pm 1.0$ & $1.9 \pm 0.06$ \\
GRS L3 $(n=32)$ & $(10 \pm 0.50) \times(13 \pm 0.48)^{* *}$ & $-76 \pm 0.97$ & $450 \pm 24$ & $-36 \pm 0.84$ & $93 \pm 2.3$ & $1.7 \pm 0.07$ \\
GRS L5 $(n=14)$ & $(17 \pm 0.81)^{* *} \times(25 \pm 1.3)^{* *}$ & $-68 \pm 1.2^{* *}$ & $90 \pm 13^{* *}$ & $-39 \pm 1.9$ & $96 \pm 2.4$ & $1.8 \pm 0.12$ \\
BF L2 $(n=21)$ & $(12 \pm 0.33) \times(19 \pm 0.81)$ & $-74 \pm 0.98$ & $130 \pm 6.5^{* *}$ & $-40 \pm 1.9^{*}$ & $100 \pm 2.5^{*}$ & $2.5 \pm 0.15^{* *}$ \\
\hline
\end{tabular}

Numbers are presented as mean \pm SEM. Using a camera lucida, the soma shape of pyramids was approximated by a triangle or a diamond, and then the length of minor and major axes was measured. Significant differences between GRS L2 neurons and the other neuron groups are indicated as asterisks $(* P<0.05$ and $* * P<0.01)$. Numbers without the asterisks were not significantly different from those for GRS L2 neurons
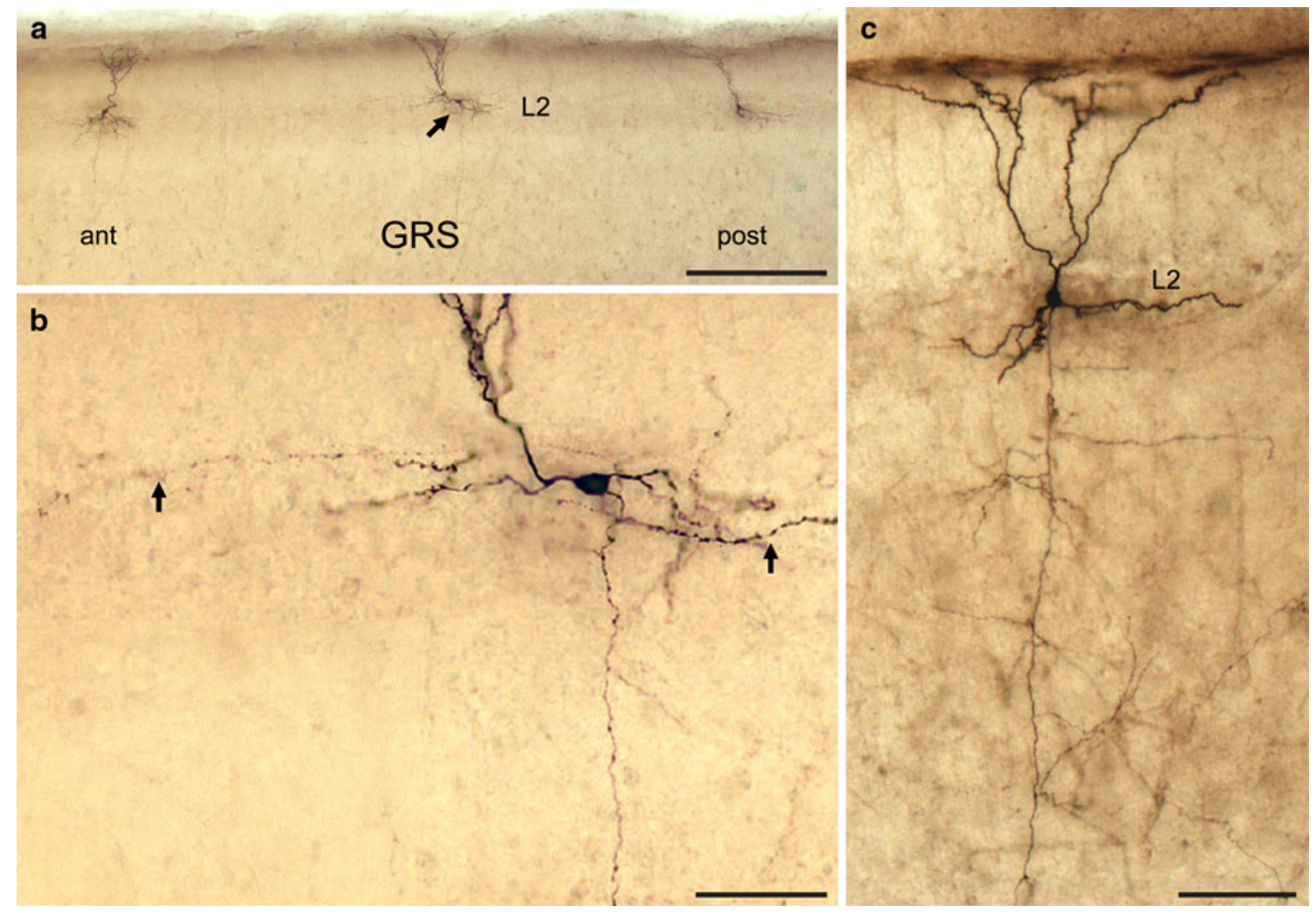

Fig. 1 Biocytin-filled layer 2 pyramidal neurons in rat GRS cortex. a Low magnification view of three biocytin-filled neurons in layer 2. Horizontal slice $(300 \mu \mathrm{m}$ in thickness) from postnatal day 31 Wistar rat. ant anterior, post posterior, scale bar $300 \mu \mathrm{m}$. b Higher magnification view of the middle neuron (arrow) in a. Two arrows indicate horizontal axon collaterals largely within layer 2. Scale bar $50 \mu \mathrm{m}$. c Another example of a layer 2 neuron. Scale bar $100 \mu \mathrm{m}$ determine the threshold, the latency of the first spike was $809 \pm 32.5 \mathrm{~ms}$. As the intensity of the depolarizing current increased, the latency of the first spike shortened, but there was still a delay in the latency of the first spike from the time of current onset (Fig. 3b, d). Spike trains evoked by a stronger current pulse $(>200 \mathrm{pA})$ exhibited a slight accommodation of firing. The instantaneous firing frequency was measured from the time difference between the $n$ and $(n+1)$ th spikes (Fig. $3 \mathrm{e})$. In response to a strong depolarizing current injection, the maximum instantaneous firing frequency was observed between the first and the second spikes, reaching a value of more than $50 \mathrm{~Hz}$. From this, the frequency gradually diminished to $30-40 \mathrm{~Hz}$ at the end of the current step (Fig. 3e, filled circle). It was confirmed that the LS firing pattern could be recorded at $36^{\circ} \mathrm{C}$ $(n=5$, Fig. $3 \mathrm{~b}$, inset).

\section{GRS layer 3 pyramidal neurons}

Pyramidal neurons in layer 3 of rat GRS were morphologically distinct from the LS neurons in layer 2. Their cell body was smaller than that of layer 2 LS neurons (Table 3; 
Fig. 2 Neurolucida reconstruction of biocytin-filled neurons. a GRS L2 neuron indicated in Fig. 1b. The cell body and dendrites are shown in black, and the axon is shown in red. L1-L6 represent layers $1-6$, respectively, and dashed lines indicate the borders between them. WM represents white matter. b Similar to a, but corresponding to GRS LS neuron in Fig 1c. Axon reconstructions are necessarily limited to the portion contained within the $300 \mu \mathrm{m}$ slice and are therefore not complete. (Same holds for the reconstructions shown in Figs. 4, 5, 6.) Scale bar $100 \mu \mathrm{m}$ is common to $\mathbf{a}$ and $\mathbf{b}$ a

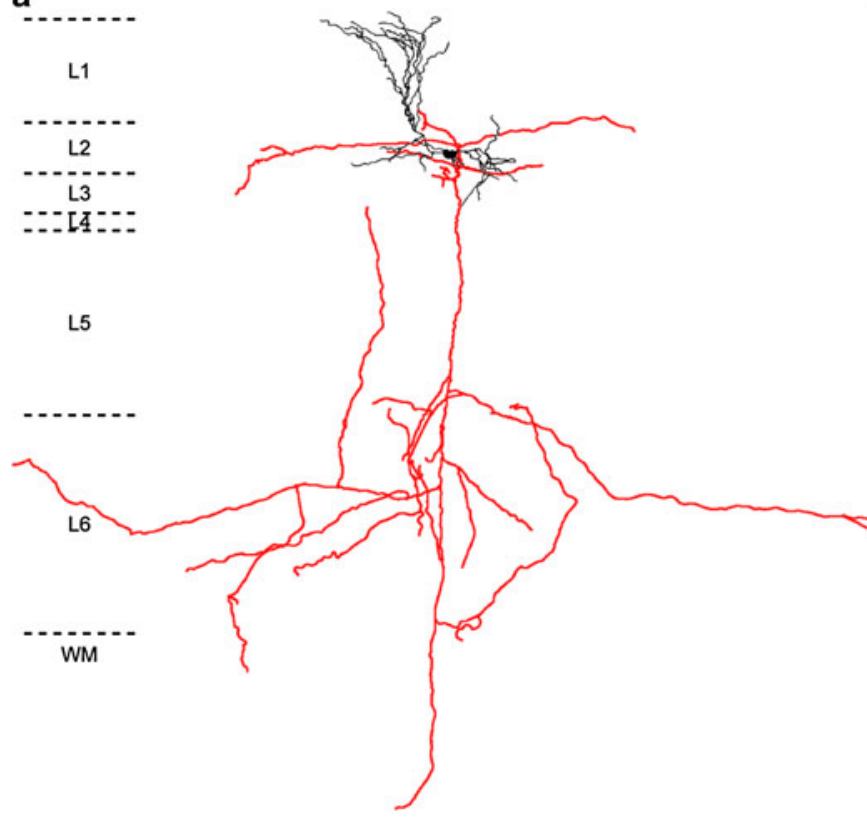

b

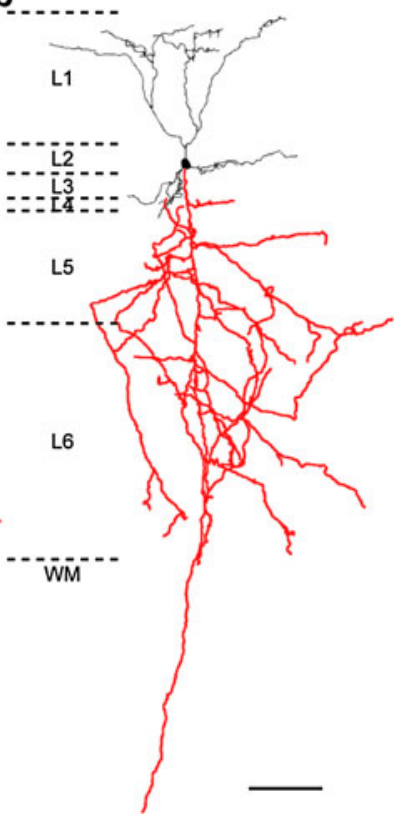

cf. Figs. 1, 2, 4a), and they had distinctly flat basal dendrites (extending straightly and parallel to the layer borders; Fig. 4a, see also Fig. 5 in Wyss et al. 1990). Despite the morphological difference, 32 of 34 neurons recorded in upper layer 3 had the same LS firing property as layer 2 neurons (Fig. 4b-f; Table 3). The remaining 2 showed a regular-spiking $(\mathrm{RS})$ firing pattern.

\section{Pyramidal neurons in layer 5 of GRS and layer 2 of BF}

Consistent with many previous reports (Connors et al. 1982; McCormick et al. 1985; Sutor and Hablitz 1989; Mason and Larkman 1990; Steriade et al. 1993; Cho et al. 2004; Otsuka and Kawaguchi 2008), we found that most of the tested pyramidal neurons in layer 5 of GRS (74\%, 14 of 19, Fig. 5a) demonstrated a RS firing pattern. Compared with GRS pyramidal neurons in layer 2, those in layer 5 of GRS had a more positive resting membrane potential $(-68 \pm 1.2 \mathrm{mV}$, Fig. 5b, c; Table 3), and a much lower input resistance $(90 \pm 13 \mathrm{M} \Omega$, Table 3 ; Fig. 5d). The remaining 5 neurons in layer 5 of GRS showed an intrinsically bursting firing pattern. Even with a depolarizing current just above threshold, the latency of the first spike was $83.4 \pm 17.2 \mathrm{~ms}$, and significantly shorter than that of LS neurons $(P<0.01$, Table 3$)$. With increasing intensity of the depolarizing current, the latency of the first spike shortened, in marked contrast with LS neurons (Fig. 5e). These neurons showed adaptation during repetitive firing and lower maximum firing frequencies (Fig. 5f).

As to the pyramidal neurons in BF layer 2, all of the cells tested $(n=21)$ demonstrated a RS firing pattern and the average input resistance showed an intermediate value (130 $\pm 6.5 \mathrm{M} \Omega$, Fig. 6b-d; Table 3) between layer 2 and layer 5 pyramids in GRS. Interestingly, the average resting membrane potential of layer 2 pyramids in $\mathrm{BF}$ was $-74 \pm 0.98 \mathrm{mV}$, close to that of GRS pyramids in layers 2 and 3. Thus, despite differences in the firing properties, there may be common factors underlying the resting membrane potential for these populations. They had a shorter average latency for the initial AP firing (120 $\pm 15 \mathrm{~ms}$, for a just-suprathreshold current, Fig. 6c) than that of LS neurons $(P<0.01)$. With increasing intensity of the depolarizing current, the latency of the first spike shortened, in marked contrast with LS neurons (Fig. 6e). These neurons showed adaptation during repetitive firing and lower maximum firing frequencies (Fig. 6f).

Biocytin fills confirmed that neurons recorded in layer 5 of the GRS and layer 2 of BF showed standard pyramidal cell morphologies (Figs. 5a, 6a, respectively).

\section{Sholl analysis of layer 2 neurons in GRS and BF}

Distinctive dendritic morphology of layer 2 pyramidal neurons in GRS, as compared with that of pyramids in layer 2 of $\mathrm{BF}$, was revealed by Sholl analysis (Fig. 7). Eight biocytin-filled RS pyramids in BF and 23 filled LS pyramids in GRS were selected for Sholl analysis. For BF layer 2 neurons, the number of intersections for apical dendrites had the highest values (about 15) at 50-60 $\mu \mathrm{m}$ from the soma (proximal dendritic zone), and gradually decreased until $350 \mu \mathrm{m}$ more distally. In contrast, for GRS layer 2 neurons, the number of intersections of the apical 


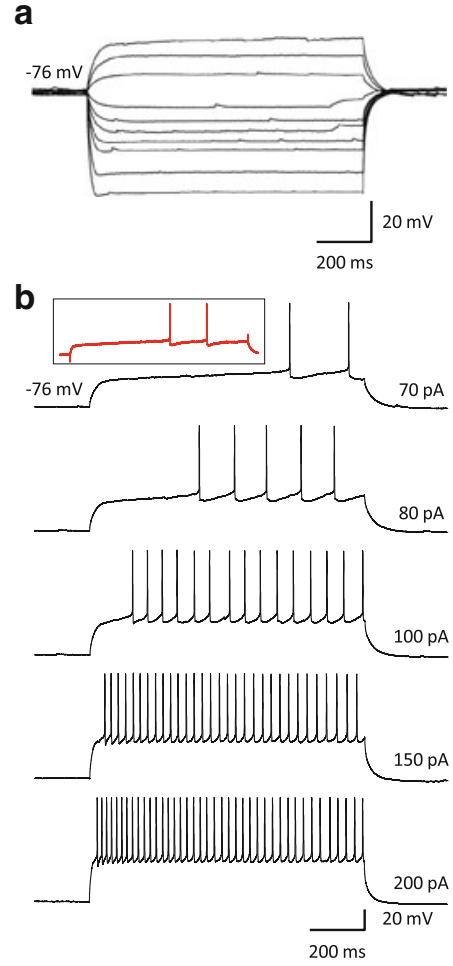

C
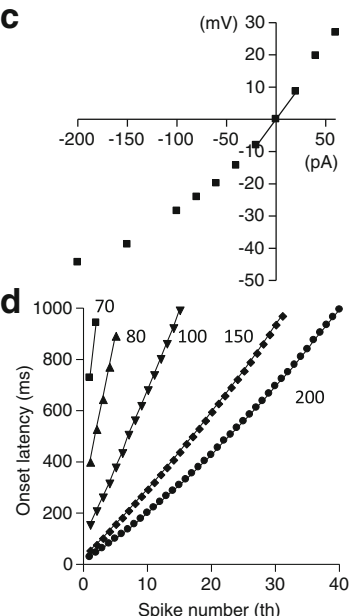

Spike number (th)

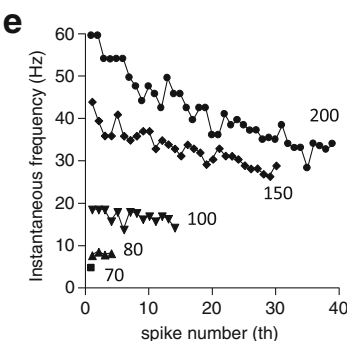

Fig. 3 A representative example of passive membrane and firing properties of a layer 2 pyramidal neuron of GRS. a Voltage responses to hyperpolarizing and sub-threshold depolarizing current injections (intensity, -200-60 pA, duration, $1 \mathrm{~s}$ ). b Voltage responses to suprathreshold depolarizing current injections. The current intensity is indicated at the end of each trace. This neuron had a resting membrane potential of $-76 \mathrm{mV}$. Note that onset of the first action potential is substantially delayed from the initiation of the current injection. Inset red trace indicates a representative example of LS firing pattern recorded at $36^{\circ} \mathrm{C}$ from another GRS L2 neuron. c Current-voltage (I-V) relationship measured $800 \mathrm{~ms}$ after the onset of step currents in a. The input resistance of this neuron was $417 \mathrm{M} \Omega$. d Onset latency of the first to $n$th spikes in response to the various intensities of the step current shown in b. Each symbol represents a different injection current intensity; squares, triangles, inverted triangles, diamonds and circles represent 70, 80, 100, 150 and $200 \mathrm{pA}$, respectively. e Inter-spike interval between $n$th to $(n+1)$ th spike, calculated from the onset latency data. Symbols are the same as those in $\mathbf{d}$

dendrites was smaller (Fig. 7a), reaching highest values (about 6) at 160-170 $\mu \mathrm{m}$ from the soma (distal dendritic zone, corresponding to layer 1A). Dendritic branching was also less for the basal dendrites of GRS LS neurons than for those of BF RS neurons (Fig. 7b).

The LS property is attributed to potassium channels

\section{Microarray data}

We identified two genes coding for different types of potassium channels, Kv1.4 and Kv4.3, that were highly expressed in GRS layer 2. (Layer 3 neurons were not investigated.) The expression ratio of these two genes in comparison with that in GRS layer 5 was 4.24 and 8.65, respectively, and was much higher than that of the other potassium channels (less than 2.53, Table 1). From these microarray data, we selected Kv1.4 and Kv4.3 channels for further analyses.

\section{In situ hybridization}

By in situ hybridization, we confirmed that the Kv1.4 signal was highly expressed in the superficial layers of GRS, but not in either GRS layer 5 or BF layer 2 (Fig. 8). The localization of Kv4.3 mRNA expression in the superficial layer of GRS has already been shown by others (Serôdio and Rudy 1998). Kv1.1 is known to be widely expressed in neocortex of mouse (Allen Brain Atlas, http://mouse.brain-map.org/), and has been investigated in supragranular pyramidal neurons of rat somatosensory and motor cortices (Guan et al. 2006).

\section{Single-cell RT-PCR}

Microarray and in situ data provide only laminar-specific resolution. We next employed single-cell RT-PCR to assess potassium channel mRNAs across individual LS pyramidal neurons in layer 2 of GRS (Fig. 9a). Expression of $\beta$-actin and $\mathrm{GABA}_{\mathrm{A}}$ receptor $\alpha 1$ subunit was used as a control for the experimental accuracy for a given cell. With this criterion, results were obtained for 21 LS neurons (Fig. 9b). Five Kv channel mRNAs were screened: Kv1.4 and $\mathrm{Kv} 4.3$, and for comparison $\mathrm{Kv} 3.1$. We also examined $\mathrm{Kv} 1.1$ and $\mathrm{Kv} 1.2$ expression in addition to Kv1.4 and $\mathrm{Kv} 4.3$, because $\mathrm{Kv} 1.1$ and $\mathrm{Kv} 1.2$ containing potassium channels have been reported to be responsible for LS firing property in medium spiny neurons in rat striatum (Shen et al. 2004) and superior colliculus (Saito and Isa 2000). Of these five channels, Kv1.1 and Kv1.4 mRNAs showed the highest expression ratio ( $81 \%$ each, $n=17)$. Kv1.1 and Kv1.4 were co-expressed in 14 neurons, and were independently expressed in 6 neurons ( 3 for Kv1.1 and 3 for Kv1.4). In total, 20 out of 21 LS neurons expressed Kv1.1 and/or Kv1.4 mRNAs. Kv4.3 mRNA was detected in the remaining one LS neuron. This cell was included in $12 \mathrm{LS}$ neurons (57\% of 21) expressing Kv4.3 mRNA. Of those, nine neurons co-expressed Kv1.1 and Kv1.4 mRNAs (see Venn diagram, Fig. 9c).

The expression ratios for Kv1.2 and Kv3.1 were rather low (24\% each; Fig. 9b). These findings are consistent with the data from gene chip and/or in situ hybridization, and point to a preferential role for the Kv 1.1, Kv1.4 and Kv4.3 channels in the generation of the LS property. 


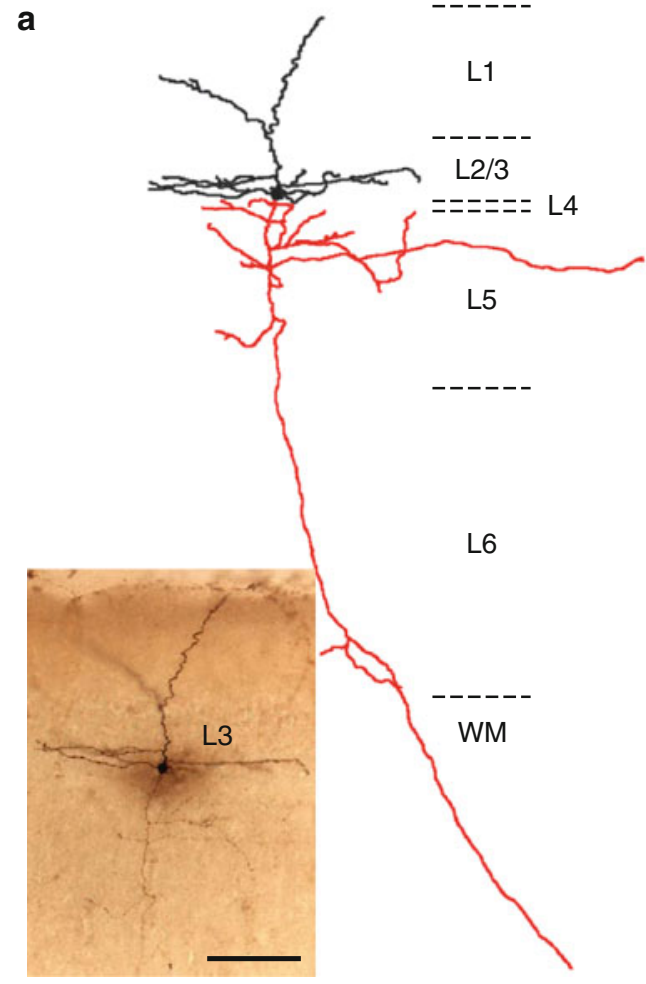

Fig. 4 Layer 3 pyramidal neurons in GRS show similar firing and intrinsic membrane properties to layer 2 pyramids. a A biocytin-filled layer 3 pyramidal neuron and its Neurolucida reconstruction. The cell body and dendrites are shown in black, and the axon is shown in red. Scale bar, $100 \mu \mathrm{m}$. b Voltage responses to hyperpolarizing and subthreshold depolarizing current injections (intensity, -140 to $50 \mathrm{pA}$, duration, $1 \mathrm{~s}$ ). c Voltage responses to supra-threshold depolarizing current injections. The current intensity is indicated at the end of each trace. This neuron had a resting membrane potential of $-77 \mathrm{mV}$.

We note that VGluT1 mRNA was expressed in all the screened neurons, consistent with other evidence that LS neurons are glutamatergic pyramidal neurons.

\section{Pharmacology}

The contribution of KV1.1, Kv1.4 and Kv4.3 channels to the LS property was further tested by pharmacological blockade of these channels (Fig. 10). In the presence of $100 \mathrm{nM}$ dendrotoxin-K, a specific blocker for Kv1.1, the latency of the first spike evoked by just-super threshold current was shortened to $24 \pm 2.2 \%$ ( $n=5$, Fig. 10a). At this concentration, DTX-K slightly depolarized the resting membrane potential and decreased the input resistance in some cases. In such cases, the resting potential was brought back to the original level by DC current injection and the amplitude of depolarizing current pulse was increased to just-super threshold level. In the presence of 1-3 $\mu \mathrm{M} \mathrm{CP}-339818$, a blocker for Kv1.4 channels at this concentration (Nguyen et al. 1996), the latency of the first spike evoked by just-super threshold current was
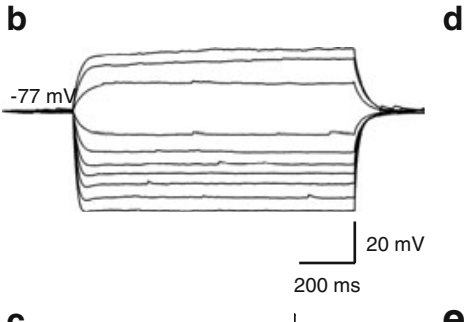

d
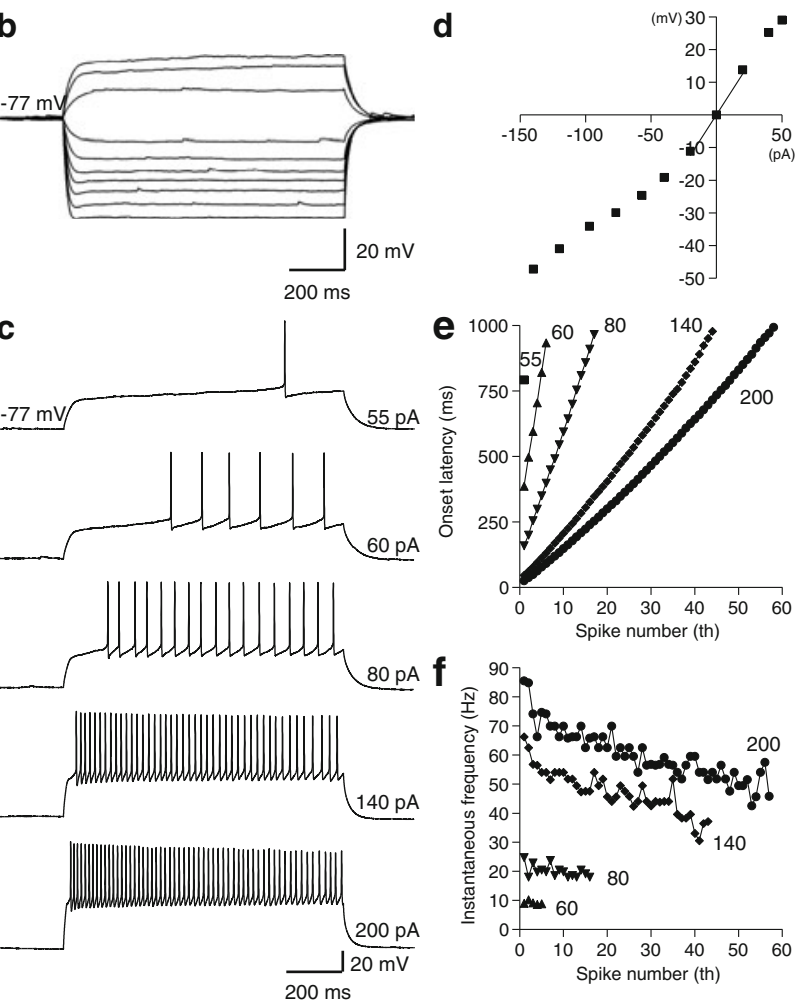

d I-V relationship measured $800 \mathrm{~ms}$ after the onset of step currents in (b). The input resistance of this neuron was $625 \mathrm{M} \Omega$. e Onset latency of the first to $n$th spikes in response to the various intensities of the step current shown in (c). Each symbol represents a different injection current intensity; square, triangle, inverted triangle, diamond and circle represent 55, 60, 80, 140 and 200 pA, respectively. f Inter-spike interval between $n$th to $(n+1)$ th spike, calculated from the onset latency data. Symbols are the same as those in (e)

shortened to $54 \pm 7.6 \%$ ( $n=8$, Fig. 10b) without a change in the resting membrane potential and the input resistance. The drug did not affect the first spike latency in 3 out of $11 \mathrm{LS}$ neurons tested. Although CP-339818 also blocks Kv1.3, we concluded that the drug specifically blocked Kv1.4 channels in our experimental condition, because the Gene-chip analysis showed that the expression of Kv1.3 was low in GRS layer 2. Nicotine (100 nM), reported to block Kv4.3 channels directly in cardiac muscle (Wang et al. 2000), also shortened the onset delay of the first spike evoked in response to a depolarizing current injection ( $48 \pm 3.5 \%, n=5$, Fig. 10c). In the presence of mecamylamine $(10 \mu \mathrm{M})$, a nonselective blocker for nicotinic acetylcholine receptors, we obtained a similar result (53 $\pm 9.9 \%, n=5$, Fig. 10d), confirming that nicotine directly suppressed Kv4.3 channels, as in the case of cardiac muscle (Wang et al. 2000). The firing pattern of 3 out of $8 \mathrm{LS}$ neurons was not affected by nicotine. Since some LS neurons were not affected by CP-339818 or nicotine, additional factors might be contributing to the LS firing property (see "Discussion"). 
a

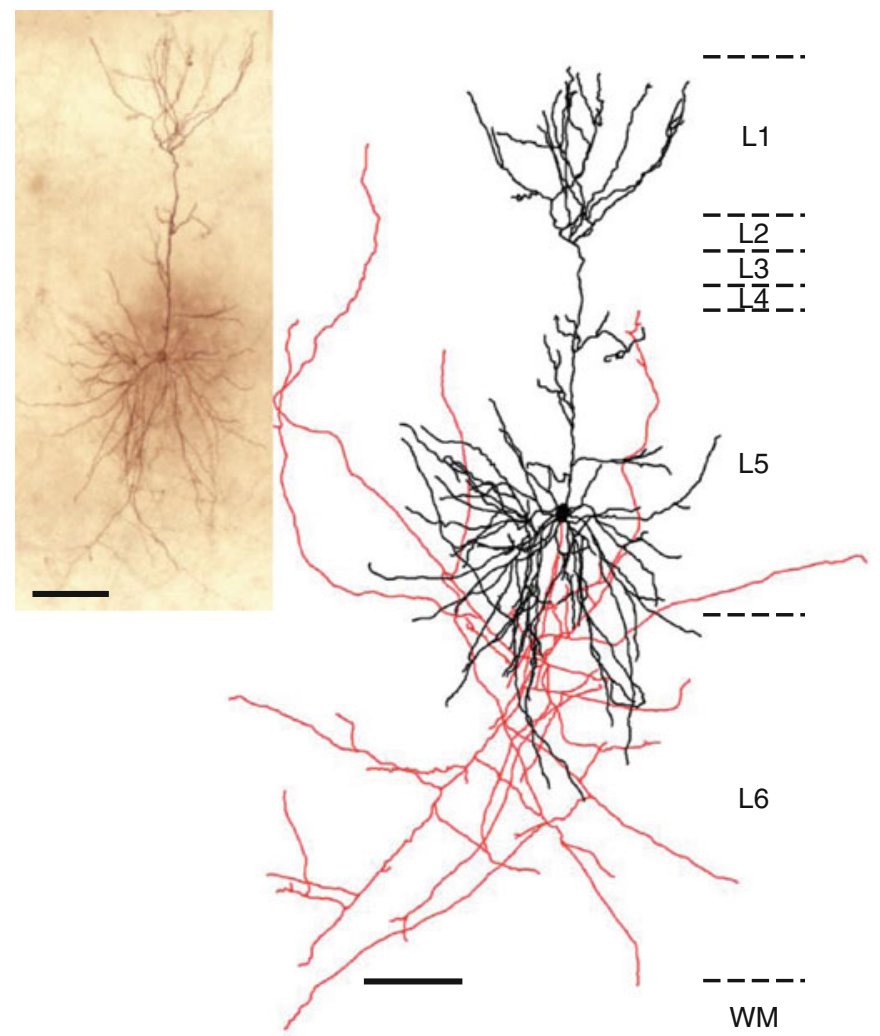

Fig. 5 A representative layer 5 pyramidal neuron in GRS, demonstrating the RS firing property. a Biocytin-filled layer 5 pyramidal neuron and its Neurolucida reconstruction. The cell body and dendrites are shown in black, and the axon is shown in red. Scale bars, $100 \mu \mathrm{m}$. b Voltage responses to hyperpolarizing and subthreshold depolarizing current injections (intensity, -500 to $150 \mathrm{pA}$, duration, $1 \mathrm{~s}$ ). c Voltage responses to supra-threshold depolarizing current injections. The current intensity is indicated at the end of each trace. This neuron had a resting membrane potential of $-63 \mathrm{mV}$.

\section{Area specificity of LS neurons}

We carried out a short survey of two other areas interconnected with GRS for the presence of LS neurons; namely, the presubiculum and perirhinal cortex. In the presubiculum, nine neurons were recorded from the superficial layer. Five of these were classified as RS, three as LS, and one as LSlike. In perirhinal cortex, neurons were identified as mainly RS ( 12 of 18 neurons from layer 2, and 7 of 12 neurons from layer 6). Of the 6 other layer 2 neurons, 1 was LS, 1 stuttering, $3 \mathrm{FS}$, and 1 single spiking. In the layer 6 sample, 1 neuron was LS, $1 \mathrm{FS}$, and 3 intrinsically bursting.

\section{Discussion}

The LS property is unusual for cortical pyramidal neurons, but has been previously described for several other cell b

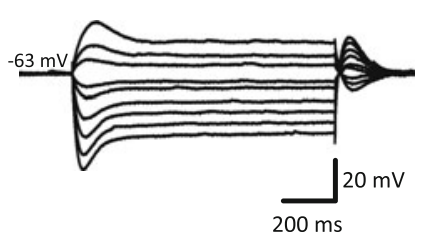

d

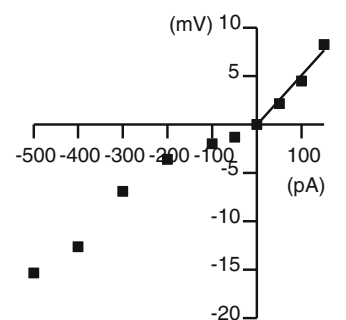

C
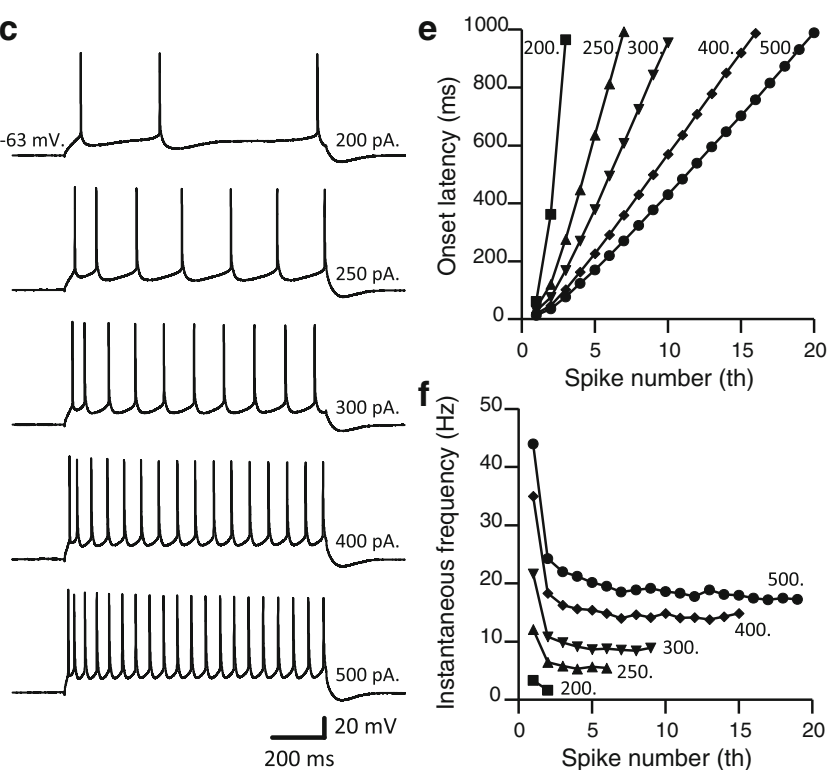

d I-V relationship measured $800 \mathrm{~ms}$ after the onset of step currents in (b). The input resistance of this neuron was $51 \mathrm{M} \Omega$. e Onset latency of the first to $n$th spikes in response to the various intensities of the step current shown in (c). Each symbol represents a different injection current intensity: square, triangle, inverted triangle, diamond and circle represent 200, 250, 300, 400 and 500 pA, respectively. f Interspike interval between $n$th to $(n+1)$ th spike, calculated from the onset latency data. Symbols are the same as those in (e)

types, in particular: medium spiny stellate neurons of the basal ganglia (Nisenbaum et al. 1994), neurons in the intermediate layers of the superior colliculus (Saito and Isa 2000), and cortical neurogliaform cells (Kawaguchi 1995; Chu et al. 2003). In barrel cortex, the delay in firing of neurogliaform cells may be associated with a slow initiation of whisker-evoked action potentials (Zhu et al. 2004).

Pyramidal cells in rat perirhinal cortex have been reported to exhibit long delays in spike initiation when injected with depolarizing current steps. Encoding over long time intervals would be appropriate to associative learning, a function identified with perirhinal cortex (Beggs et al. 2000; McGann et al. 2001). LS neurons in perirhinal cortex were reported in high percentages in both the upper layers (19 of 26 neurons) and layer 6 (74 of 86 neurons). In our screen of perirhinal cortex, we identified two neurons as late spiking (one in layer 2, from a total of 18 ; one in layer 6 from a total of 12). Other investigators have 
a

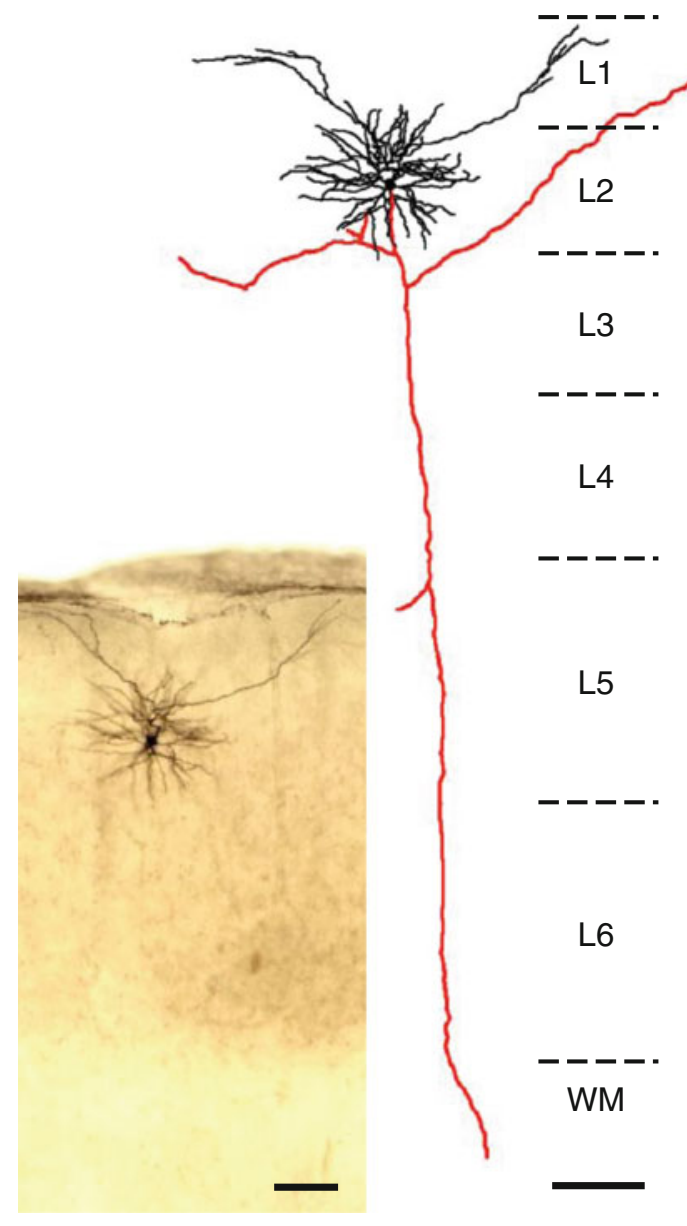

b

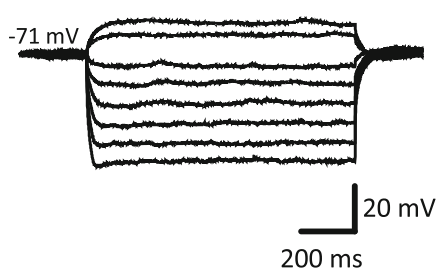

C
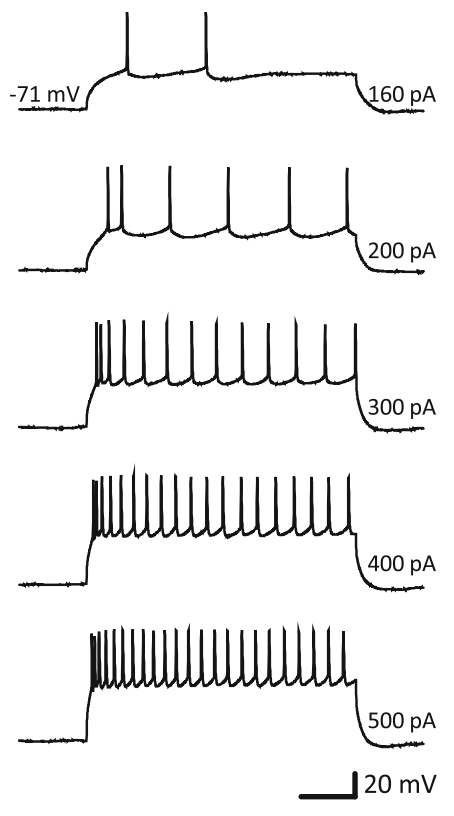

$200 \mathrm{~ms}$ d
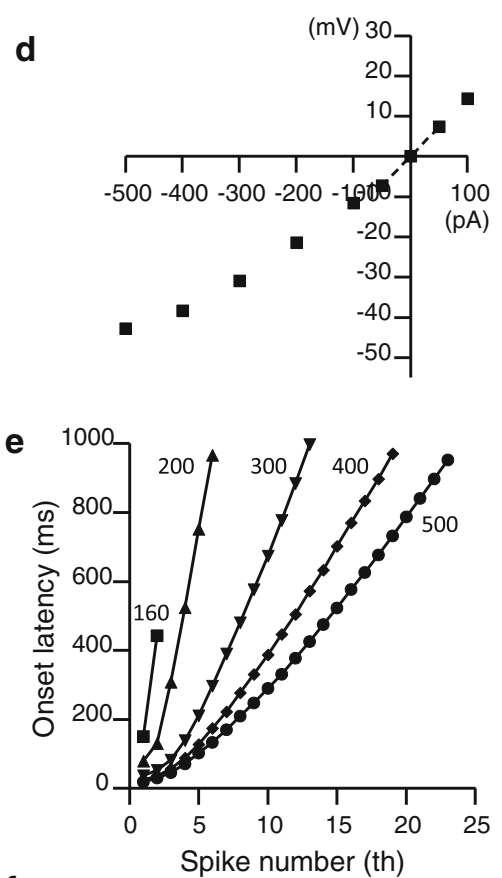

$f$ N.

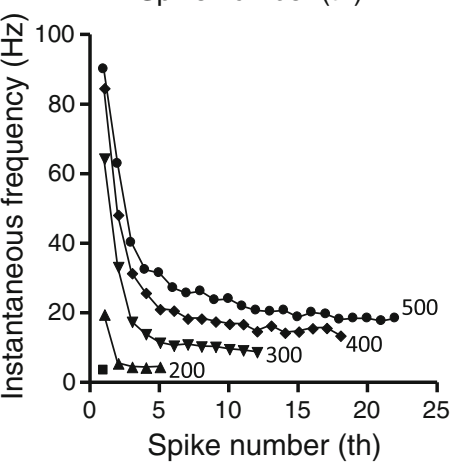

Fig. 6 A representative layer 2 pyramidal neuron in BF, with a typical RS firing property. a Biocytin-filled layer 2 pyramidal neuron and its Neurolucida reconstruction. The cell body and dendrites are shown in black, and the axon is shown in red. Scale bars $100 \mu \mathrm{m}$. b Voltage responses to hyperpolarizing and sub-threshold depolarizing current injections (intensity, $-500-100 \mathrm{pA}$, duration, $1 \mathrm{~s}$ ). c Voltage responses to supra-threshold depolarizing current injections. The current intensity is indicated at the end of each trace. This neuron had a resting membrane potential of $-71 \mathrm{mV}$. d I-V

identified perirhinal neurons in the upper layers as behaving as RS relay cells (Biella et al. 2007). The apparent discrepancy in the abundance of LS neurons is surprising but may be due to sublaminar or other variations in the location of the recording sites, and/or differences in the recording conditions.

What is the significance of LS neurons in the rat GRS? In previous discussions, the LS property has been interpreted as required for synaptic integration in a certain context. The GRS is known to contain head-direction cells (Chen et al. 1994; Cho and Sharp 2001), and has been implicated in aspects of learning and memory in a wide range of behaviors such as visual and vestibular relationship measured $800 \mathrm{~ms}$ after the onset of step currents in (b). The input resistance of this example neuron was $146 \mathrm{M} \Omega$. e Onset latency of the first to $n$th spikes in response to the various intensities of the step current shown in (c). Each symbol represents a different injection current intensity: squares, triangles, inverted triangles, diamonds and circles represent 160, 200, 300, 400 and $500 \mathrm{pA}$, respectively. f Inter-spike interval between $n$th to $(n+1)$ th spike, calculated from the onset latency data. Symbols are the same as those in $(\mathbf{e})$

integration, path integration, and spatial navigation (Cooper and Mizumori 1999, 2001; Cooper et al. 2001; Harker and Whishaw 2002; Vann and Aggleton 2002; Vann et al. 2003; van Groen et al. 2004). This functional profile could be consistent with a LS property, where synaptic inputs are compared or integrated during the delay interval. On the other hand, it is clear that the LS property per se is associated with a range of neuronal phenotypes, including both GABAergic and glutamatergic neurons in several different regions (see above). The exact mechanism and significance of the LS property may depend on area-specific circuitry.

Our results on the physiological distinctness of GRS layer 2 pyramids, are in accord with several recent studies 

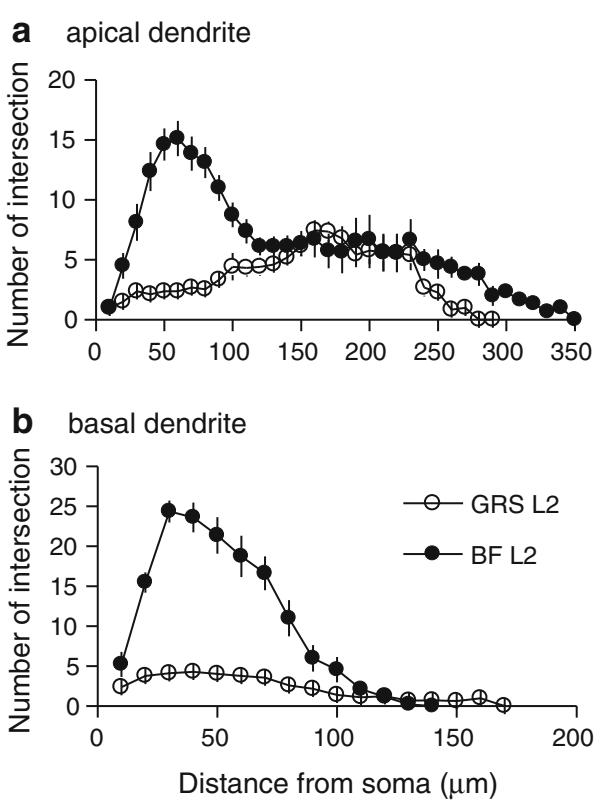

Fig. 7 Sholl analysis of the apical and basal dendrites of layer 2 pyramidal neurons in GRS and BF. a The number of intersections of concentric circles made by the apical dendrites of GRS layer 2 (open circles) and of BF layer 2 neurons (filled circles), plotted against the distance from soma. b Similar to a, but for the basal dendrites

GRS

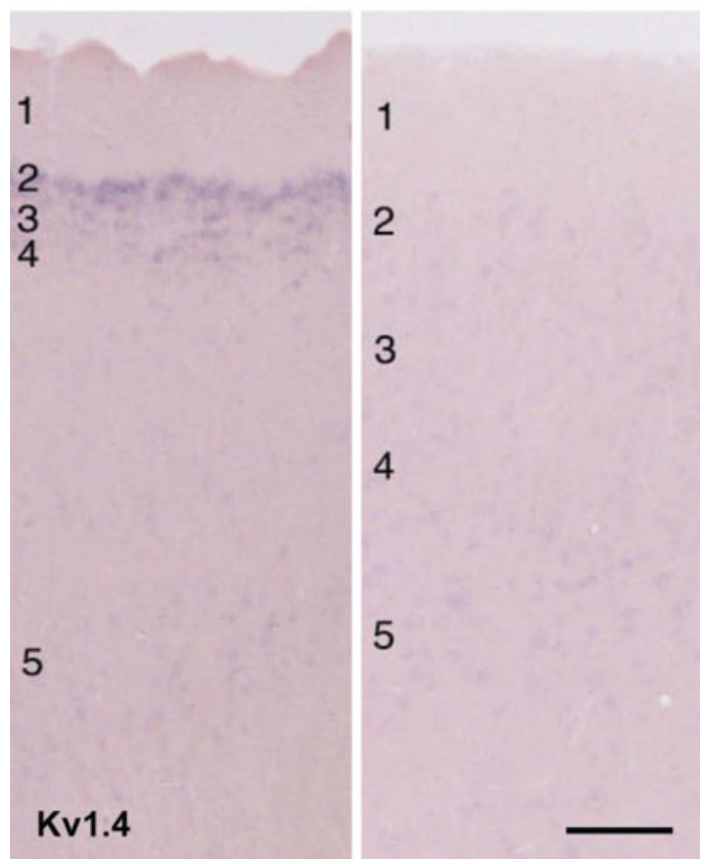

Fig. 8 In situ hybridization for Kv1.4 mRNA in GRS and BF cortices. Cortical layers numbered at left. Scale bar $300 \mu \mathrm{m}$

that demonstrate layer-specific dysregulation in the GRS after anterior thalamic lesions (Poirier and Aggleton 2009; Amin et al. 2010). That is, activity-related markers show either decreased levels in superficial GRS (c-fos, zif268, 5ht2rc, kcnab2) or, for one marker (cox6b), increased levels (Amin et al. 2010). These results highlight the role of GRS as part of an extended network, notably involving the anterior thalamic nucleus and the hippocampal formation. The distal dendritic tufts of layer 2 neurons, in upper layer 1 , are potential postsynaptic candidates of projections from the anteroventral thalamus (Shibata 1993), which converge in this layer with GABAergic input from CA1 hippocampus (Miyashita and Rockland 2007).

The GRS could have multiple roles in an extended thalamic-hippocampal network. Working memory tasks, for example, increase immediate early gene activity in the GRS during spatial learning and navigation based on both internal and external cues (light and dark conditions; Pothuizen et al. 2009). No layer-specific patterns were identified in these experiments. However, another recent experiment has reported a selective change in $c$-fos expression in layer 2 GRS neurons during a spatial, but not during a non-spatial version of the Morris water maze in mice (Czajkowski et al. 2008).

Another possibility is that the LS neurons as a population are involved in synchronous activity. The GRS is recurrently interconnected with hippocampal structures, and is known to be one of several regions which can independently generate theta-range oscillations (Kirk and Mackay 2003; Talk et al. 2004). Synchronous firing could be achieved by extensive axonal interconnectivity, such as has been demonstrated for LS neurogliaform neurons in cortical layer 1 (Chu et al. 2003). However, although GRS neurons in layer 2 have horizontal, intralaminar collaterals, these are not unusually abundant, nor are collaterals restricted to this layer. The conspicuous bundling of apical dendrites is another candidate mechanism for synchronous firing, either via direct dendro-dendritic appositions among the apical dendrites or via the intermingled parvalbuminpositive dendrites (Ichinohe and Rockland 2002). In a previous electron microscopic study (Ichinohe et al. 2003), we reported direct appositions in the upper layers between distal dendrites of layer 5 GRS neurons, identified by immunolabeling for OCAM. In that study, appositions between putative layer 2 apical dendritic trunks were observed in single sections, but this observation requires confirmation with serial section reconstruction or identifying markers specific for layer 2 apical dendrites. Classical gap junctions were not observed between pyramidal cell dendrites, although these were found between parvalbumin-positive dendrites (Ichinohe et al. 2003).

Potassium channels

The large family of potassium channels has been extensively investigated; and the expression, distribution, and biophysical properties have been characterized for multiple 
a

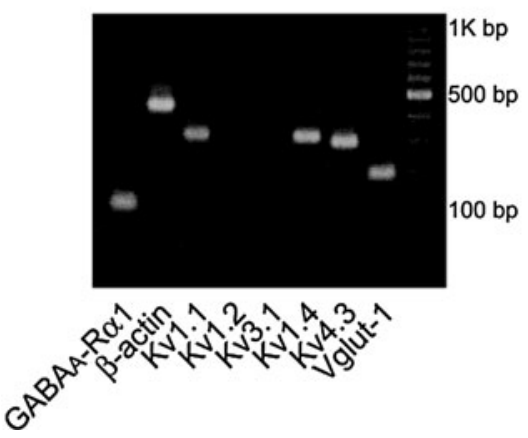

b

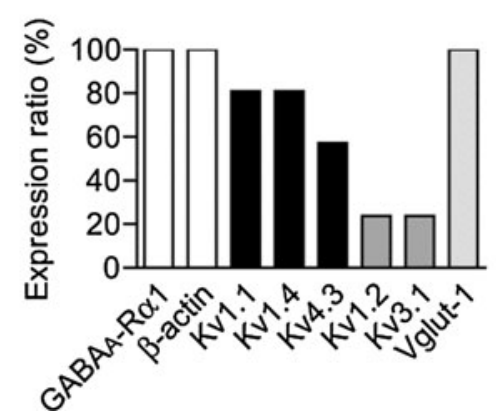

C

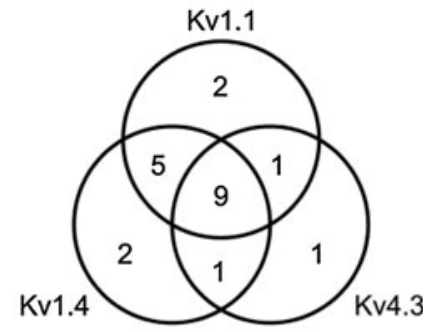

Fig. 9 a Single-cell RT-PCR for one layer 2 neuron in GRS. Eight genes were tested. Amplified cDNA fragments were confirmed by $2 \%$ agarose gel electrophoresis, with a 100 bp DNA ladder marker. Note the presence of genes for Kv1.1, Kv1.4 and Kv4.3. For this cell, genes for Kv1.2 and Kv3.1 were not found (two dark lanes). b Expression ratio of each of these genes in $21 \mathrm{GABA}_{\mathrm{A}}$ receptor $\alpha 1$ subunit and $\beta$-actin positive LS neurons. $\mathbf{c}$ Venn diagram showing the number of cells expressing Kv1.1, Kv1.4 and Kv4.3 messages. Note that all of the LS neurons $(n=21)$ expressed at least one of three Kv channel messages
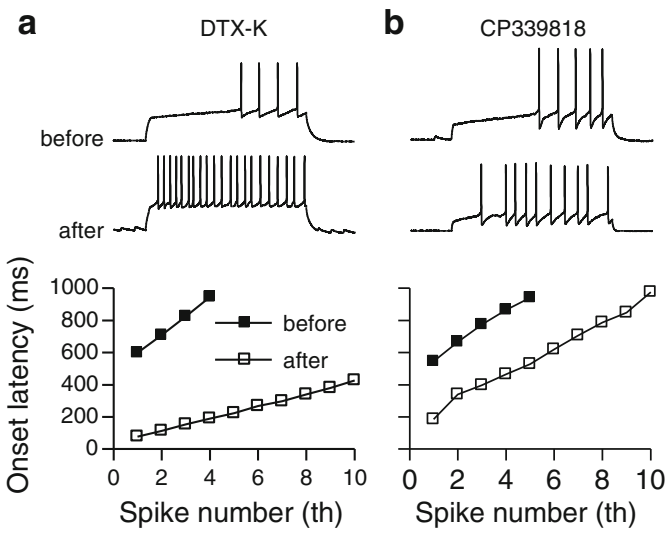
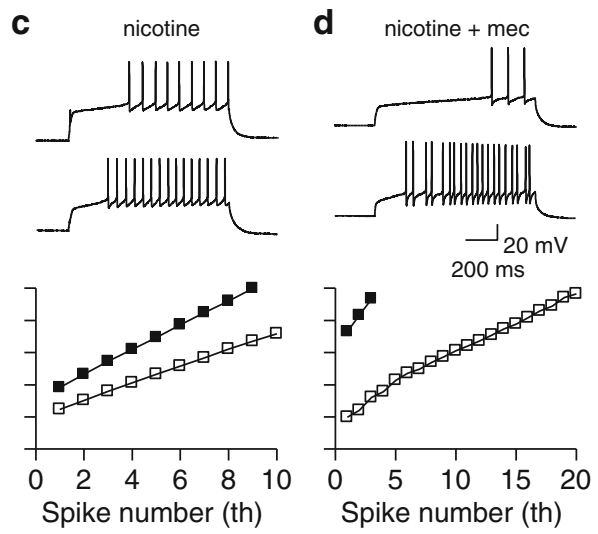

Fig. 10 a A representative example showing the effect of $100 \mathrm{nM}$ DTX-K on the LS firing pattern. Voltage responses to a depolarizing current for a layer $2 \mathrm{LS}$ neuron, before and $10 \mathrm{~min}$ after the administration of DTX-K are shown. The lower graph shows the change in the onset latency of spikes in the same LS neuron. Note that

subunits (Gabel and Nisenbaum 1998; Shen et al. 2004; Guan et al. 2006; Vacher et al. 2008). Single-cell RT-PCR, immunocytochemistry, and whole-cell recordings with specific peptide toxins have established that neocortical pyramidal cells express multiple delayed rectifier Kv1 $\alpha$ subunits, likely to play a role in regulating cell excitability (Guan et al. 2006, 2007).

We have demonstrated in this report that Kv1.1, Kv1.4 and Kv4.3 channels are highly expressed in layer 2 pyramidal neurons in GRS and provided evidence for their contribution to the LS firing property in those pyramids. $\mathrm{Kv1.1}$ is classified as a delayed rectifier, while Kv1.4 and Kv4.3 generate the so-called "A-type" rapidly inactivating potassium currents $\left(I_{\mathrm{A}}\right)$. Our single-cell RT-PCR experiment showed that the Kv1.1 channels were expressed in the LS neurons in layer 2 of GRS, but not selectively for this layer and cell population (Table 2). Indeed, it has been reported that Kv1.1 channels are widely expressed in the onset latency of the first spike was reduced from 660 to $80 \mathrm{~ms}$ after DTX-K application. b Similar to a, showing the effect of $3 \mu \mathrm{M}$ CP-339818. c Similar to a, showing the effect of $100 \mathrm{nM}$ nicotine. d Similar to a showing the effect of $100 \mathrm{nM}$ nicotine in the presence of mecamylamine $(10 \mu \mathrm{M})$

supragranular neocortical pyramidal neurons (Guan et al. 2006). The firing property of these neurons is mostly RS (McCormick et al. 1985; Sutor and Hablitz 1989; Mason and Larkman 1990; Cho et al. 2004), as was found in our present results (Fig. 6). However, Kv1.1- and Kv1.2-containing potassium channels have been proposed to regulate the LS firing property in striatal medium spiny neurons (Nisenbaum et al. 1994; Gabel and Nisenbaum 1998; Shen et al. 2004). Correspondingly, we found that application of dendrotoxin-K (100 nM), specific blocker for the Kv1.1 channel at this concentration, reduced the onset latency of the first spike in layer 2 LS neurons of GRS (Fig. 10). Our pharmacological experiments also show effects of $I_{\mathrm{A}}$ in layer 2 LS pyramids. This current has been attributed to several combinations of $\mathrm{Kv}$ channels (Gabel and Nisenbaum 1998). In cultured Drosophila neurons, Sh and Shal channels, mediating $I_{\mathrm{A}}$-like rapidly inactivating currents, have been reported to contribute to the formation of a 
"delayed" firing property. Interaction of rapidly and slowly inactivating currents has been implicated in specific firing patterns in Drosophila (Peng and Wu 2007). In developing and cultured cerebellar granule cells, suppression of $I_{\mathrm{A}}$ by expressing a dominant negative mutant $\mathrm{Kv} 4.2$ resulted in shortening of latency before the first spike generation (Shibata et al. 2000). Whether the same channel combinations characterize LS layer 3 pyramidal cells requires further investigation.

In summary, by microarray, in situ hybridization, and single-cell RT-PCR, we showed a clear association of delayed rectifier and A-type potassium channels, Kv1.1, Kv1.4 and Kv4.3, with neurons in layer 2 of the GRS. Further experiments will be needed to determine whether these channels additionally contribute to other properties (e.g., Kv4.3-mediated currents as underlying rhythmic activity in hippocampal interneurons, Bourdeau et al. 2007), and to determine the full panoply of channel interactions responsible for the LS firing property.

\section{Conclusion}

In conclusion, layer 2 GRS neurons in the rat are a distinctive population, with a common output (i.e., callosally projecting; Wyss et al. 1990), strong apical dendritic bundling, and shared unusual firing properties. A recent study reports that layer 2 GRS neurons are developmentally distinctive, characterized by late migration from the subventricular zone during the first postnatal week (Zgraggen et al. 2011). Some layer 3 neurons have callosal outputs and show LS firing properties, although layer 3 neurons have a slightly different dendritic morphology. How these features subserve aspects of learning and memory remains for further investigations.

Acknowledgments We thank Dr. George Dragoi for helpful comments and discussion. This work was supported by RIKEN Brain Science Institute and by KAKENHI 22500370.

Open Access This article is distributed under the terms of the Creative Commons Attribution License which permits any use, distribution, and reproduction in any medium, provided the original author(s) and the source are credited.

\section{References}

Aggleton JP, O'Mara SM, Vann SD, Wright NF, Tsanov M, Erichsen JT (2010) Hippocampal-anterior thalamic pathways for memory: uncovering a network of direct and indirect actions. Eur $\mathbf{J}$ Neurosci 31:2292-2307

Albasser MM, Poirier GL, Warburton EC, Aggleton JP (2007) Hippocampal lesions halve immediate-early gene protein counts in retrosplenial cortex: distal dysfunctions in a spatial memory system. Eur J Neurosci 26:1254-1266
Amin E, Wright N, Poirier GL, Thomas KL, Erichsen JT, Aggleton JP (2010) Selective lamina dysregulation in granular retrosplenial cortex (area 29) after anterior thalamic lesions: an in situ hybridization and trans-neuronal tracing study in rats. Neuroscience 169:1255-1267

Beggs JM, Moyer JR, McGann JP, Brown TH (2000) Prolonged synaptic integration in perirhinal cortical neurons. J Neurophysiol 83:3294-3298

Biella GR, Spaiardi P, Jimenez-Moreno R, Magistretti J, Taglietti V, Toselli M (2007) A fast transient outward current in layer II/III neurons of rat perirhinal cortex. Pflugers Arch 455:515-525

Bourdeau ML, Morin F, Laurent CE, Azzi M, Lacaille J (2007) Kv4.3-mediated A-type $\mathrm{K}+$ currents underlie rhythmic activity in hippocampal interneurons. J Neurosci 27:1942-1953

Chen LL, Lin LH, Green EJ, Barnes CA, McNaughton BL (1994) Head-direction cells in the rat posterior cortex. I. Anatomical distribution and behavioral modulation. Exp Brain Res 101:8-23

Cho J, Sharp PE (2001) Head direction, place, and movement correlates for cells in the rat retrosplenial cortex. Behav Neurosci 115:3-25

Cho R, Segawa S, Mizuno A, Kaneko T (2004) Intracellularly labeled pyramidal neurons in the cortical areas projecting to the spinal cord. I. Electrophysiological properties of pyramidal neurons. Neurosci Res 50:381-394

Chu Z, Galarreta M, Hestrin S (2003) Synaptic interactions of latespiking neocortical neurons in layer 1. J Neurosci 23:96-102

Connors BW, Gutnick MJ, Prince DA (1982) Electrophysiological properties of neocortical neurons in vitro. J Neurophysiol 48:1302-1320

Cooper BG, Mizumori SJ (1999) Retrosplenial cortex inactivation selectively impairs navigation in darkness. Neuroreport 10:625-630

Cooper BG, Mizumori SJ (2001) Temporary inactivation of the retrosplenial cortex causes a transient reorganization of spatial coding in the hippocampus. J Neurosci 21:3986-4001

Cooper BG, Manka TF, Mizumori SJ (2001) Finding your way in the dark: the retrosplenial cortex contributes to spatial memory and navigation without visual cues. Behav Neurosci 115:1012-1028

Czajkowski R, Wiltgen BJ, Guzman Karlsson M, Jayaprakash B, Barth AL, Silva AJ (2008) Insights into spatial memory formation in retrosplenial cortex. Program No. 689.12. 2008 Neuroscience Meeting Planner. Society for Neuroscience, Washington, DC (online)

Gabel LA, Nisenbaum ES (1998) Biophysical characterization and functional consequences of a slowly inactivating potassium current in neostriatal neurons. J Neurophysiol 79:19892002

Garden DLF, Massey PV, Caruana DA, Johnson B, Warburton EC, Aggleton JP, Bashir ZI (2009) Anterior thalamic lesions stop synaptic plasticity in retrosplenial cortex slices: expanding the pathology of diencephalic amnesia. Brain 132:1847-1857

Guan D, Lee JCF, Tkatch T, Surmeier DJ, Armstrong WE, Foehring RC (2006) Expression and biophysical properties of Kv1 channels in supragranular neocortical pyramidal neurones. J Physiol (Lond) 571:371-389

Guan D, Lee JCF, Higgs MH, Spain WJ, Foehring RC (2007) Functional roles of $\mathrm{Kv1}$ channels in neocortical pyramidal neurons. J Neurophysiol 97:1931-1940

Harker KT, Whishaw IQ (2002) Place and matching-to-place spatial learning affected by rat inbreeding (Dark-Agouti, Fischer 344) and albinism (Wistar, Sprague-Dawley) but not domestication (wild rat vs. Long-Evans, Fischer-Norway). Behav Brain Res 134:467-477

Ichinohe N, Rockland KS (2002) Parvalbumin positive dendrites colocalize with apical dendritic bundles in rat retrosplenial cortex. Neuroreport 13:757-761 
Ichinohe N, Yoshihara Y, Hashikawa T, Rockland KS (2003) Developmental study of dendritic bundles in layer 1 of the rat granular retrosplenial cortex with special reference to a cell adhesion molecule, OCAM. Eur J Neurosci 18:1764-1774

Ichinohe N, Knight A, Ogawa M, Ohshima T, Mikoshiba K, Yoshihara Y, Terashima T, Rockland KS (2008) Unusual patch-matrix organization in the retrosplenial cortex of the reeler mouse and Shaking rat Kawasaki. Cereb Cortex 18:1125-1138

Kawaguchi Y (1995) Physiological subgroups of nonpyramidal cells with specific morphological characteristics in layer II/III of rat frontal cortex. J Neurosci 15:2638-2655

Keene CS, Bucci DJ (2009) Damage to the retrosplenial cortex produces specific impairments in spatial working memory. Neurobiol Learn Mem 91:408-414

Kirk IJ, Mackay JC (2003) The role of theta-range oscillations in synchronizing and integrating activity in distributed mnemonic networks. Cortex 39:993-1008

Konishi T (2004) Three-parameter lognormal distribution ubiquitously found in cDNA microarray data and its application to parametric data treatment. BMC Bioinformatics 5:5

Konishi T (2006) Detection and restoration of hybridization problems in affymetrix GeneChip data by parametric scanning. Genome Inform 17:100-109

Konishi T (2008) Data distribution of short oligonucleotide expression arrays and its application to the construction of a generalized intellectual framework. Stat Appl Genet Mol Biol 7: Article25

Liss B, Roeper J (2004) Correlating function and gene expression of individual basal ganglia neurons. Trends Neurosci 27(8):475481

Mason A, Larkman A (1990) Correlations between morphology and electrophysiology of pyramidal neurons in slices of rat visual cortex. II. Electrophysiology. J Neurosci 10:1415-1428

McCormick DA, Connors BW, Lighthall JW, Prince DA (1985) Comparative electrophysiology of pyramidal and sparsely spiny stellate neurons of the neocortex. J Neurophysiol 54:782-806

McGann JP, Moyer JR, Brown TH (2001) Predominance of latespiking neurons in layer VI of rat perirhinal cortex. J Neurosci 21:4969-4976

Miyashita T, Rockland KS (2007) GABAergic projections from the hippocampus to the retrosplenial cortex in the rat. Eur J Neurosci 26:1193-1204

Miyashita T, Wintzer M, Kurotani $\mathrm{T}$, Konishi $\mathrm{T}$, Ichinohe $\mathrm{N}$, Rockland KS (2010) Neurotrophin-3 is involved in the formation of apical dendritic bundles in cortical layer 2 of the rat. Cereb Cortex 20:229-240

Mizumori SJ, Cooper BG, Leutgeb S, Pratt WE (2000) A neural systems analysis of adaptive navigation. Mol Neurobiol 21:57-82

Moyer JR, McNay EC, Brown TH (2002) Three classes of pyramidal neurons in layer $\mathrm{V}$ of rat perirhinal cortex. Hippocampus $12: 218-234$

Nguyen A, Kath JC, Hanson DC, Biggers MS, Canniff PC, Donovan CB, Mather RJ, Bruns MJ, Rauer H, Aiyar J, Lepple-Wienhues A, Gutman GA, Grissmer S, Cahalan MD, Chandy KG (1996) Novel nonpeptide agents potently block the C-type inactivated conformation of Kv1.3 and suppress $\mathrm{T}$ cell activation. Mol Pharmacol 50:1672-1679

Nisenbaum ES, Xu ZC, Wilson CJ (1994) Contribution of a slowly inactivating potassium current to the transition to firing of neostriatal spiny projection neurons. J Neurophysiol 71:11741189

Otsuka T, Kawaguchi Y (2008) Firing-pattern-dependent specificity of cortical excitatory feed-forward subnetworks. J Neurosci 28:11186-11195
Peng I, Wu C (2007) Differential contributions of Shaker and Shab $\mathrm{K}+$ currents to neuronal firing patterns in Drosophila. J Neurophysiol 97:780-794

Poirier GL, Aggleton JP (2009) Post-surgical interval and lesion location within the limbic thalamus determine extent of retrosplenial cortex immediate-early gene hypoactivity. Neuroscience 160:452-469

Pothuizen HHJ, Aggleton JP, Vann SD (2008) Do rats with retrosplenial cortex lesions lack direction? Eur J Neurosci 28:2486-2498

Pothuizen HHJ, Davies M, Albasser MM, Aggleton JP, Vann SD (2009) Granular and dysgranular retrosplenial cortices provide qualitatively different contributions to spatial working memory: evidence from immediate-early gene imaging in rats. Eur $\mathrm{J}$ Neurosci 30:877-888

Saito Y, Isa T (2000) Voltage-gated transient outward currents in neurons with different firing patterns in rat superior colliculus. J Physiol (Lond) 528(Pt 1):91-105

Serôdio P, Rudy B (1998) Differential expression of Kv4K+ channel subunits mediating subthreshold transient $\mathrm{K}+$ (A-type) currents in rat brain. J Neurophysiol 79:1081-1091

Shen W, Hernandez-Lopez S, Tkatch T, Held JE, Surmeier DJ (2004) Kv1.2-containing $\mathrm{K}+$ channels regulate subthreshold excitability of striatal medium spiny neurons. J Neurophysiol 91:13371349

Shibata H (1993) Efferent projections from the anterior thalamic nuclei to the cingulate cortex in the rat. J Comp Neurol 330:533-542

Shibata R, Nakahira K, Shibasaki K, Wakazono Y, Imoto K, Ikenaka $\mathrm{K}$ (2000) A-type $\mathrm{K}+$ current mediated by the Kv4 channel regulates the generation of action potential in developing cerebellar granule cells. J Neurosci 20:4145-4155

Shibata H, Kondo S, Naito J (2004) Organization of retrosplenial cortical projections to the anterior cingulate, motor, and prefrontal cortices in the rat. Neurosci Res 49:1-11

Sripanidkulchai K, Wyss JM (1986) Thalamic projections to retrosplenial cortex in the rat. J Comp Neurol 254:143-165

Steriade M, Nuñez A, Amzica F (1993) A novel slow $(<1 \mathrm{~Hz})$ oscillation of neocortical neurons in vivo: depolarizing and hyperpolarizing components. J Neurosci 13:3252-3265

Sutor B, Hablitz JJ (1989) EPSPs in rat neocortical neurons in vitro. I. Electrophysiological evidence for two distinct EPSPs. J Neurophysiol 61:607-620

Talk A, Kang E, Gabriel M (2004) Independent generation of theta rhythm in the hippocampus and posterior cingulate cortex. Brain Res 1015:15-24

Vacher H, Mohapatra DP, Trimmer JS (2008) Localization and targeting of voltage-dependent ion channels in mammalian central neurons. Physiol Rev 88:1407-1447

van Groen T, Wyss JM (1990) Connections of the retrosplenial granular a cortex in the rat. J Comp Neurol 300:593-606

van Groen T, Kadish I, Wyss JM (2004) Retrosplenial cortex lesions of area Rgb (but not of area Rga) impair spatial learning and memory in the rat. Behav Brain Res 154:483-491

Vann SD, Aggleton JP (2002) Extensive cytotoxic lesions of the rat retrosplenial cortex reveal consistent deficits on tasks that tax allocentric spatial memory. Behav Neurosci 116:85-94

Vann SD, Honey RC, Aggleton JP (2003) Lesions of the mammillothalamic tract impair the acquisition of spatial but not nonspatial contextual conditional discriminations. Eur J Neurosci 18:2413-2416

Vann SD, Aggleton JP, Maguire EA (2009) What does the retrosplenial cortex do? Nat Rev Neurosci 10:792-802

Vogt BA, Peters A (1981) Form and distribution of neurons in rat cingulate cortex: areas 32, 24, and 29. J Comp Neurol 195:603-625 
Vogt BA, Rosene DL, Peters A (1981) Synaptic termination of thalamic and callosal afferents in cingulate cortex of the rat. J Comp Neurol 201:265-283

Wang H, Shi H, Zhang L, Pourrier M, Yang B, Nattel S, Wang Z (2000) Nicotine is a potent blocker of the cardiac A-type $\mathrm{K}(+)$ channels. Effects on cloned Kv4.3 channels and native transient outward current. Circulation 102:1165-1171

Wright NF, Erichsen JT, Vann SD, O’Mara SM, Aggleton JP (2010) Parallel but separate inputs from limbic cortices to the mammillary bodies and anterior thalamic nuclei in the rat. J Comp Neurol 518:2334-2354

Wyss JM, Van Groen T (1992) Connections between the retrosplenial cortex and the hippocampal formation in the rat: a review. Hippocampus 2:1-11
Wyss JM, Van Groen T, Sripanidkulchai K (1990) Dendritic bundling in layer I of granular retrosplenial cortex: intracellular labeling and selectivity of innervation. J Comp Neurol 295:33-42

Zgraggen E, Boitard M, Roman I, Kanemitsu M, Potter G, Salmon P, Vutskits L, Dayer AG, Kiss JZ (2011) Early postnatal migration and development of layer II pyramidal neurons in the rodent cingulate/retrosplenial cortex. Cereb Cortex. doi:10.1093/ cercor/bhr097

Zhu Y, Stornetta RL, Zhu JJ (2004) Chandelier cells control excessive cortical excitation: characteristics of whisker-evoked synaptic responses of layer $2 / 3$ nonpyramidal and pyramidal neurons. J Neurosci 24:5101-5108 